\title{
Macroeconomic Implications of Changes in the Term Premium
}

\author{
Glenn D. Rudebusch, Brian P. Sack, and Eric T. Swanson
}

\begin{abstract}
Linearized New Keynesian models and empirical no-arbitrage macro-finance models offer little insight regarding the implications of changes in bond term premiums for economic activity. This paper investigates these implications using both a structural model and a reduced-form framework. The authors show that there is no structural relationship running from the term premium to economic activity, but a reduced-form empirical analysis does suggest that a decline in the term premium has typically been associated with stimulus to real economic activity, which contradicts earlier results in the literature. (JEL E43, E44, E52, G12)
\end{abstract}

Federal Reserve Bank of St. Louis Review, July/August 2007, 89(4), pp. 241-69.

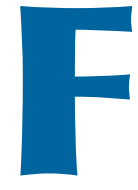
rom June 2004 through June 2006, the Federal Reserve gradually raised the federal funds rate from 1 percent to $5^{1 / 4}$ percent. Despite this 425-basis-point increase in the short-term rate, long-term interest rates remained at remarkably low levels, with the 10 -year Treasury yield averaging $4 \frac{1}{4}$ percent in both 2004 and 2005 and ending September 2006 at just a little above $4 \frac{1}{2}$ percent. The apparent lack of sensitivity of long-term interest rates to the large rise in short rates surprised many observers, as such behavior contrasted sharply with interest rate movements during past policytightening cycles. ${ }^{1}$ Perhaps the most famous expression of this surprise was provided by then-Chairman of the Federal Reserve Alan Greenspan in monetary policy testimony before Congress in February 2005, in which he noted that "the broadly unanticipated behavior of world bond markets remains a conundrum."

\footnotetext{
1 For example, from January 1994 to February 1995, the Federal Reserve raised the federal funds rate by 3 percentage points and the 10 -year rate rose by 1.7 percentage points.
}

The puzzlement over the recent low and relatively stable levels of long-term interest rates has generated much interest in trying to understand both the source of these low rates and their economic implications. In addressing these issues, it is useful to divide the yield on a long-term bond into an expected-rate component that reflects the anticipated average future short rate for the maturity of the bond and a term-premium component that reflects the compensation that investors require for bearing the interest rate risk from holding long-term instead of short-term debt. Chairman Greenspan's later July 2005 monetary policy testimony suggested that the conundrum likely involved movements in the latter component, noting that "a significant portion of the sharp decline in the ten-year forward one-year rate over the past year appears to have resulted from a fall in term premiums." This interpretation has been supported by estimates from various finance and macro-finance models that indicate that the recent relatively stable 10-year Treasury yield reflects that the upward revisions

Glenn D. Rudebusch is a senior vice president and associate director of research and Eric T. Swanson is a research advisor at the Federal Reserve Bank of San Francisco. Brian P. Sack is a vice president at Macroeconomic Advisers. The views expressed in this paper are the authors' and do not necessarily reflect official positions of the Federal Reserve System. The authors thank John Cochrane, Monika Piazzesi, and Jessica Wachter for helpful comments and suggestions. Michael McMorrow, Vuong Nguyen, and David Thipphavong provided excellent research assistance.

(C) 2007, The Federal Reserve Bank of St. Louis. Articles may be reprinted, reproduced, published, distributed, displayed, and transmitted in their entirety if copyright notice, author name(s), and full citation are included. Abstracts, synopses, and other derivative works may be made only with prior written permission of the Federal Reserve Bank of St. Louis. 
to expected future short rates that accompanied the monetary policy tightening were offset, on balance, by a decline in the term premium (e.g., Kim and Wright, 2005, and Rudebusch, Swanson, and $\mathrm{Wu}, 2006){ }^{2}$

It is this recent experience of a declining term premium in long-term rates that motivates our paper. We examine what is known-both in theory and from the data-about the macroeconomic implications of changes in the term premium. This topic is especially timely and important because of the practical implications of the recent low term premium for the conduct of monetary policy. Specifically, as noted by Federal Reserve Governor Donald Kohn (2005), "the decline in term premiums in the Treasury market of late may have contributed to keeping long-term interest rates relatively low and, consequently, may have supported the housing sector and consumer spending more generally." Furthermore, any such macroeconomic impetus would alter the appropriate setting of the stance of monetary policy, as described by Federal Reserve Chairman Ben Bernanke (2006):

To the extent that the decline in forward rates can be traced to a decline in the term premium...the effect is financially stimulative and argues for greater monetary policy restraint, all else being equal. Specifically, if spending depends on long-term interest rates, special factors that lower the spread between short-term and long-term rates will stimulate aggregate demand. Thus, when the term premium declines, a higher short-term rate is required to obtain the long-term rate and the overall mix of financial conditions consistent with maximum sustainable employment and stable prices.

Under this "practitioner" view, which is also prevalent among market analysts and private sector macroeconomic forecasters, the recent fall in the term premium provided a boost to real economic activity and, therefore, optimal mone-

2 Of course, as we discuss in detail below, such decompositions of the long rate into expected rates and a term premium are subject to considerable uncertainty. tary policy should have followed a relatively more restrictive path as a counterbalance. ${ }^{3}$

Unfortunately, this practitioner view of the macroeconomic and monetary policy implications of a drop in the term premium is not supported by the simple linearized New Keynesian model of aggregate output that is currently so popular among economic researchers. In that model, output is determined by a forward-looking IS curve:

$$
y_{t}=\beta E_{t} y_{t+1}-\frac{1}{\gamma}\left(i_{t}-E_{t} \pi_{t+1}\right)+e_{t},
$$

where $y_{t}$ denotes aggregate output and $i_{t}-E_{t} \pi_{t+1}$ is the one-period ex ante real interest rate. Solving this equation forward, output can be expressed as a function of short-term real interest rates alone:

$$
y_{t}=-\frac{1}{\gamma} E_{t} \sum_{j=0}^{\infty} \beta^{j}\left(i_{t+j}-\pi_{t+1+j}\right)+e_{t} .
$$

According to this equation, it is the expected path of the short-term real interest rate that determines the extent of intertemporal substitution and hence current output. Long-term interest rates matter only because they embed expectations of future short-term interest rates (as in McGough, Rudebusch, and Williams, 2005). Taken literally, this simple analytic framework does not allow shifts in the term premium to affect output; therefore, according to this model, the recent decline in the term premium should be ignored when constructing optimal monetary policy, and the only important consideration should be the restraining influence of the rising expected-rate component.

Given these contradictory practitioner and New Keynesian views about the macroeconomic implications of changes in the term premium, this paper considers what economic theory more generally implies about this relationship as well as what the data have to say. We start in the next section by examining a structural dynamic stochastic general equilibrium (DSGE) framework

\footnotetext{
3 For example, in a January 2005 commentary, the private forecasting firm Macroeconomic Advisers argued that the low term premium was keeping financial conditions accommodative and "would require the Fed to 'do more' with the federal funds rate to achieve the desired rate of growth.”
} 
that can completely characterize the relationship between the term premium and the economy. In this framework, unlike its linearized New Keynesian descendant, there are important connections between term premiums and the economy. Unfortunately, given theoretical uncertainties and computational complexities, the model cannot be taken directly to the data, so it provides only qualitative insights about the macroeconomic implications of changes in term premiums, not quantitative empirical assessments.

To uncover such empirical assessments, the third section surveys the recent empirical macrofinance literature, which links the behavior of long-term interest rates to the economy, with varying degrees of economic structure (e.g., Ang and Piazzesi, 2003, and Rudebusch and Wu, 2003, denoted RW). However, although this new literature has made interesting advances in understanding how macroeconomic conditions affect the term premium, it has made surprisingly little progress toward understanding the reverse relationship. Indeed, restrictions are typically imposed in these models that either eliminate any effects of the term premium on the economy or require the term premium to affect the economy in the same way as other sources of long-rate movements. Accordingly, as yet, this literature is not very useful for investigating whether there are important macroeconomic implications of movements in the term premium.

In contrast, as reviewed in the fourth section, several papers have directly investigated the predictive power of movements in the term premium on subsequent gross domestic product (GDP) growth (e.g., Favero, Kaminska, and Söderström, 2005, and Hamilton and Kim, 2002), but because these analyses rely on simple reduced-form regressions, their structural interpretation is unclear. Nevertheless, taken at face value, the bulk of the evidence suggests that decreases in the term premium are followed by slower output growthclearly contradicting the practitioner view (as well as the simple New Keynesian view). However, we reconsider such regressions and provide some new empirical evidence that supports the view taken by many central bankers and market analysts that a decline in the term premium typically has been associated with stimulus to the economy.

The final section concludes by describing some practical lessons for monetary policymakers when confronted with a sizable movement in the term premium.

\section{A STRUCTURAL MODEL OF THE TERM PREMIUM AND THE ECONOMY}

In this section, we use a standard structural macroeconomic DSGE framework to study the relationship between the term premium and the economy. In principle, such a framework can completely characterize this relationship; however, in practice the DSGE asset-pricing framework has a number of well-known computational and practical limitations that keep it from being a useful empirical workhorse. Nevertheless, the framework can provide interesting qualitative insights, as we will now show.

\section{An Asset-Pricing Representation of the Term Premium}

As in essentially all asset pricing, the fundamental equation that we assume prices assets in the economy is the stochastic discounting relationship:

$$
p_{t}=E_{t}\left[m_{t+1} p_{t+1}\right]
$$

where $p_{t}$ denotes the price of a given asset at time $t$ and $m_{t+1}$ denotes the stochastic discount factor that is used to value the possible statecontingent payoffs of the asset in period $t+1$ (where $p_{t+1}$ implicitly includes any dividend or coupon payouts). ${ }^{4}$ Specifically, the price of a default-free $n$-period zero-coupon bond that pays one dollar at maturity, $p_{t}^{(n)}$, satisfies

\footnotetext{
4 Cochrane (2001) provides a comprehensive treatment of this asset-pricing framework. As Cochrane discusses, a stochastic discount factor that prices all assets in the economy can be shown to exist under very weak assumptions; for example, the assumptions of free portfolio formation and the law of one price are sufficient, although these do require that investors are small with respect to the market.
} 


$$
p_{t}^{(n)}=E_{t}\left[m_{t+1} p_{t+1}^{(n-1)}\right],
$$

where $p_{t}^{(0)}=1$ (the price of one dollar delivered at time $t$ is one dollar).

We can use this framework to formalize the decomposition of bond yields described in the introduction, with the term premium defined as the difference between the yield on an $n$-period bond and the expected average short-term yield over the same $n$ periods. ${ }^{5}$ Let $i_{t}^{(n)}$ denote the continuously compounded $n$-period bond yield (with $i_{t} \equiv i_{t}^{(1)}$ ); then the term premium can be computed from the stochastic discount factor in a straightforward manner:

$$
\begin{aligned}
& i_{t}^{(n)}-\frac{1}{n} E_{t} \sum_{j=0}^{n-1} i_{t+j}=-\frac{1}{n} \log p_{t}^{(n)}+\frac{1}{n} E_{t} \sum_{j=0}^{n-1} \log p_{t+j}^{(1)} \\
& =-\frac{1}{n} \log E_{t}\left[\prod_{j=1}^{n} m_{t+j}\right]+\frac{1}{n} E_{t} \sum_{j=1}^{n} \log E_{t+j-1} m_{t+j} .
\end{aligned}
$$

Of course, equation (5) does not have an easy interpretation without imposing additional structure on the stochastic discount factor, such as conditional log-normality. Nonetheless, even in this general form, equation (5) highlights an important point: The term premium is not exogenous, as a change in the term premium can only be due to changes in the stochastic discount factor. Thus, to investigate the relationship between the term premium and the economy in a structural model, we must first specify why the stochastic discount factor in the model is changing.

In general, the stochastic discount factor will respond to all of the various shocks affecting the economy, including innovations to monetary policy, technology, and government purchases. Of course, these different types of shocks also have implications for the determination of output and other economic variables. Thus, we would expect the correlation between the term premium and output to depend on which structural shock

\footnotetext{
5 This definition of the term premium (given by the left-hand side of equation (5)) differs from the one used in the theoretical finance literature by a convexity term, which arises because the expected log price of a long-term bond is not equal to the log of the expected price. Our analysis is not sensitive to this adjustment; indeed, some of our empirical term-premium measures are convexityadjusted and some are not, and they are all highly correlated over our sample.
}

was driving the change in the term premium. We next elaborate on this point using a simple structural model.

\section{A Benchmark DSGE Structural Model}

The expression for the term premium described by equation (5) is quite general but not completely transparent, because it does not impose any structure on the stochastic discount factor. Thus, to illuminate the structural relationship between the term premium and the macroeconomy, we introduce a simple benchmark New Keynesian DSGE model.

The basic features of the model are as follows. Households are representative and have preferences over consumption and labor streams given by

$$
\max E_{t} \sum_{t=0}^{\infty} \beta^{t}\left(\frac{\left(c_{t}-b h_{t}\right)^{1-\gamma}}{1-\gamma}-\chi_{0} \frac{l_{t}^{1+\chi}}{1+\chi}\right),
$$

where $\beta$ denotes the household's discount factor, $c_{t}$ denotes consumption in period $t, l_{t}$ denotes labor, $h_{t}$ denotes a predetermined stock of consumption habits, and $\gamma, \chi, \chi_{0}$, and $b$ are parameters. We set $h_{t}=C_{t-1}$, the level of aggregate consumption in the previous period, so that the habit stock is external to the household. There is no investment in physical capital in the model, but there is a one-period nominal risk-free bond and a long-term default-free nominal consol that pays one dollar every period in perpetuity (under our baseline parameterization, the duration of the consol is about 25 years). The economy also contains a continuum of monopolistically competitive firms with fixed, firm-specific capital stocks that set prices according to Calvo contracts and hire labor competitively from households. The firms' output is subject to an aggregate technology shock. Furthermore, we assume there is a government that levies stochastic, lump-sum taxes on households and destroys the resources it collects. Finally, there is a monetary authority that sets the one-period nominal interest rate according to a Taylor-type policy rule:

$$
i_{t}=\rho_{i} i_{t-1}+\left(1-\rho_{i}\right)\left[i^{*}+g_{y}\left(y_{t}-y_{t-1}\right)+g_{\pi} \pi_{t}\right]+\varepsilon_{t}^{i},
$$


where $i^{\star}$ denotes the steady-state nominal interest rate, $y_{t}$ denotes output, $\pi_{t}$ denotes the inflation rate (equal to $P_{t} / P_{t-1}-1$ ), $\varepsilon_{t}^{i}$ denotes a stochastic monetary policy shock, and $\rho_{i}$, $g_{y}$, and $g_{\pi}$ are parameters. ${ }^{6}$ This basic structure is very common in the macroeconomics literature, so details of the specification are presented in the appendix.

In equilibrium, the representative household's optimal consumption choice satisfies the Euler equation:

(8) $\left(c_{t}-b c_{t-1}\right)^{-\gamma}=\beta \exp \left(i_{t}\right) E_{t}\left(c_{t+1}-b c_{t}\right)^{-\gamma} P_{t} / P_{t+1}$,

where $P_{t}$ denotes the dollar price of one unit of consumption in period $t$. The stochastic discount factor is given by

$$
m_{t+1}=\frac{\beta\left(c_{t+1}-b c_{t}\right)^{-\gamma}}{\left(c_{t}-b c_{t-1}\right)^{-\gamma}} \frac{P_{t}}{P_{t+1}} .
$$

The nominal consol's price, $p_{t}^{(\infty)}$, thus satisfies

$$
p_{t}^{(\infty)}=1+E_{t} m_{t+1} p_{t+1}^{(\infty)} .
$$

We define the risk-neutral consol price, $p_{t}^{(\infty) \mathrm{rn}}$, to be

$$
p_{t}^{(\infty) r n}=1+\exp \left(-i_{t}\right) E_{t} p_{t+1}^{(\infty) r n} .
$$

The implied term premium is then given by ${ }^{7}$

$$
\log \left(\frac{p_{t}^{(\infty)}}{p_{t}^{(\infty)}-1}\right)-\log \left(\frac{p_{t}^{(\infty) r n}}{p_{t}^{(\infty) r n}-1}\right) .
$$

Having specified the benchmark model, we can now solve the model and compute the responses of the term premium and the other variables of the model to economic shocks. Parameters

\footnotetext{
${ }^{6}$ Note that the interest rate rule we use here is a function of output growth rather than the output gap. We chose to use output growth in the rule because definitions of potential output (and hence the output gap) can sometimes be controversial. In any case, our results are not very sensitive to the inclusion of output growth in the policy rule. For example, if we set the coefficient on output growth to zero, all of our results are essentially unchanged. We also follow much of the literature in assuming an "inertial" policy rule with gradual adjustment and i.i.d. policy shocks. However, Rudebusch (2002 and 2006) argues for an alternative specification with serially correlated policy shocks and little such gradualism.

7 The continuously compounded yield to maturity of the consol is given by $\log [p /(p-1)]$. To express the term premium in annualized basis points rather than in logs, equation (12) must be multiplied by 40,000 . We obtained qualitatively similar results using alternative term-premium measures in the model, such as the term premium on a two-period zero-coupon bond.
}

of the model are given in the appendix. We solve the model by the standard procedure of approximation around the nonstochastic steady state, but because the term premium is zero in a first-order approximation and constant in a second-order approximation, we compute a third-order approximation to the solution of the model using the $n$ th-order approximation package described in Swanson, Anderson, and Levin (2006), called perturbation AIM.

In Figures 1, 2, and 3, we present the impulse response functions of the term premium and output to a 1-percentage-point monetary policy shock, a 1 percent aggregate technology shock, and a 1 percent government purchases shock, respectively. These impulse responses demonstrate that the relationship between the term premium and output depends on the type of structural shock. For monetary policy and technology shocks, a rise in the term premium is associated with current and future weakness in output. By contrast, for a shock to government purchases, a rise in the term premium is associated with current and future output strength. Thus, even the sign of the correlation between the term premium and output depends on the nature of the underlying shock that is hitting the economy.

A second observation to draw from Figures 1, 2 , and 3 is that, in each case, the response of the term premium is quite small, amounting to less than one-third of 1 basis point, even at the peak of the response! Indeed, the average level of the term premium for the consol in this model is only 15.7 basis points. ${ }^{8}$ This finding foreshadows

8 From the point of view of a second- or third-order approximation, this result is not surprising, because only under extreme curvature or large stochastic variances do second- or third-order terms matter much in a macroeconomic model. Some research has arguably employed such model modifications to account for the term premium. For example, Hördahl, Tristani, and Vestin (2006b) assume that the technology shock has a quarterly standard deviation of 2.5 percent and a persistence of 0.986 . Adopting these two parameter values in our model causes the term premium to rise to 141 basis points. Ravenna and Seppälä (2006) assume a shock to the marginal utility of consumption, with a persistence of 0.95 and a quarterly standard deviation of 8 percent. A similar shock in our model boosts the term premium to 41 basis points. Wachter (2006) assumes a habit parameter $(b)$ of 0.961 , which in our model boosts the term premium to 22.3 basis points. Thus, we are largely able to replicate some of these authors' findings; nonetheless, we believe that our benchmark parameter values are the most standard ones in the macroeconomics literature (e.g., Christiano, Eichenbaum, and Evans, 2005). 
Rudebusch, Sack, Swanson

Figure 1

Impulse Responses to a 1-Percentage-Point Federal Funds Rate Shock
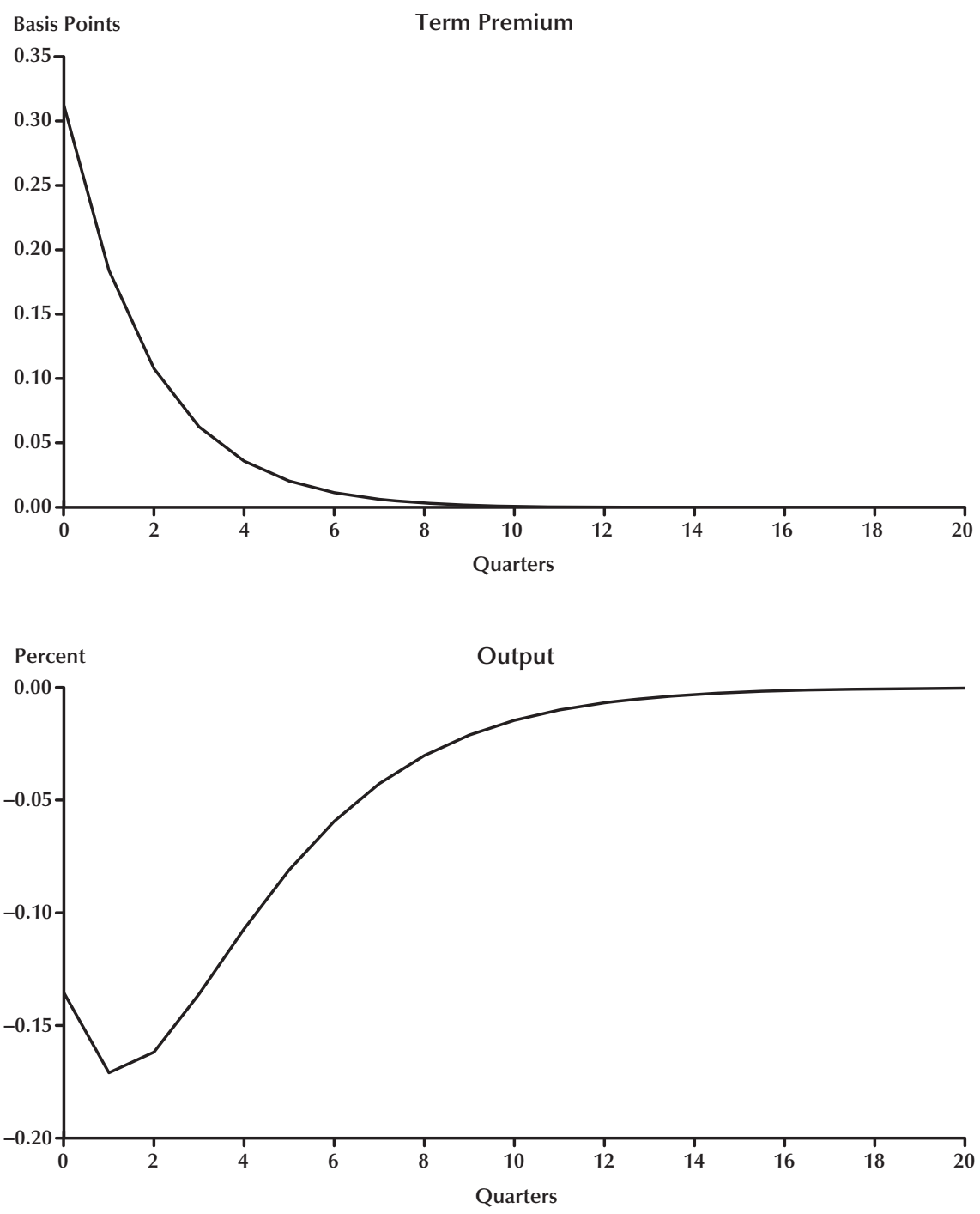
Figure 2

Impulse Responses to a 1 Percent Technology Shock
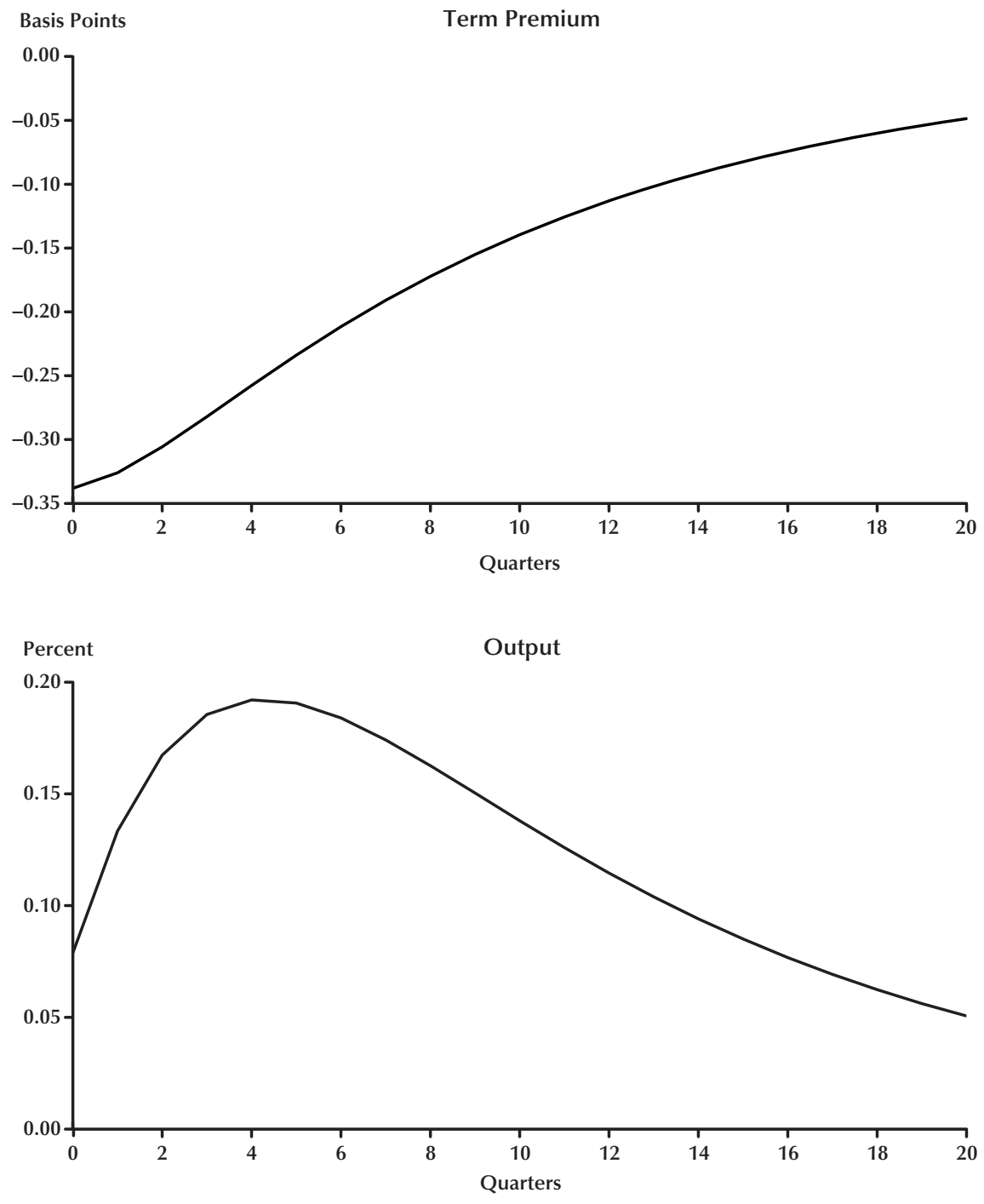
Rudebusch, Sack, Swanson

Figure 3

Impulse Responses to a 1 Percent Government Purchases Shock
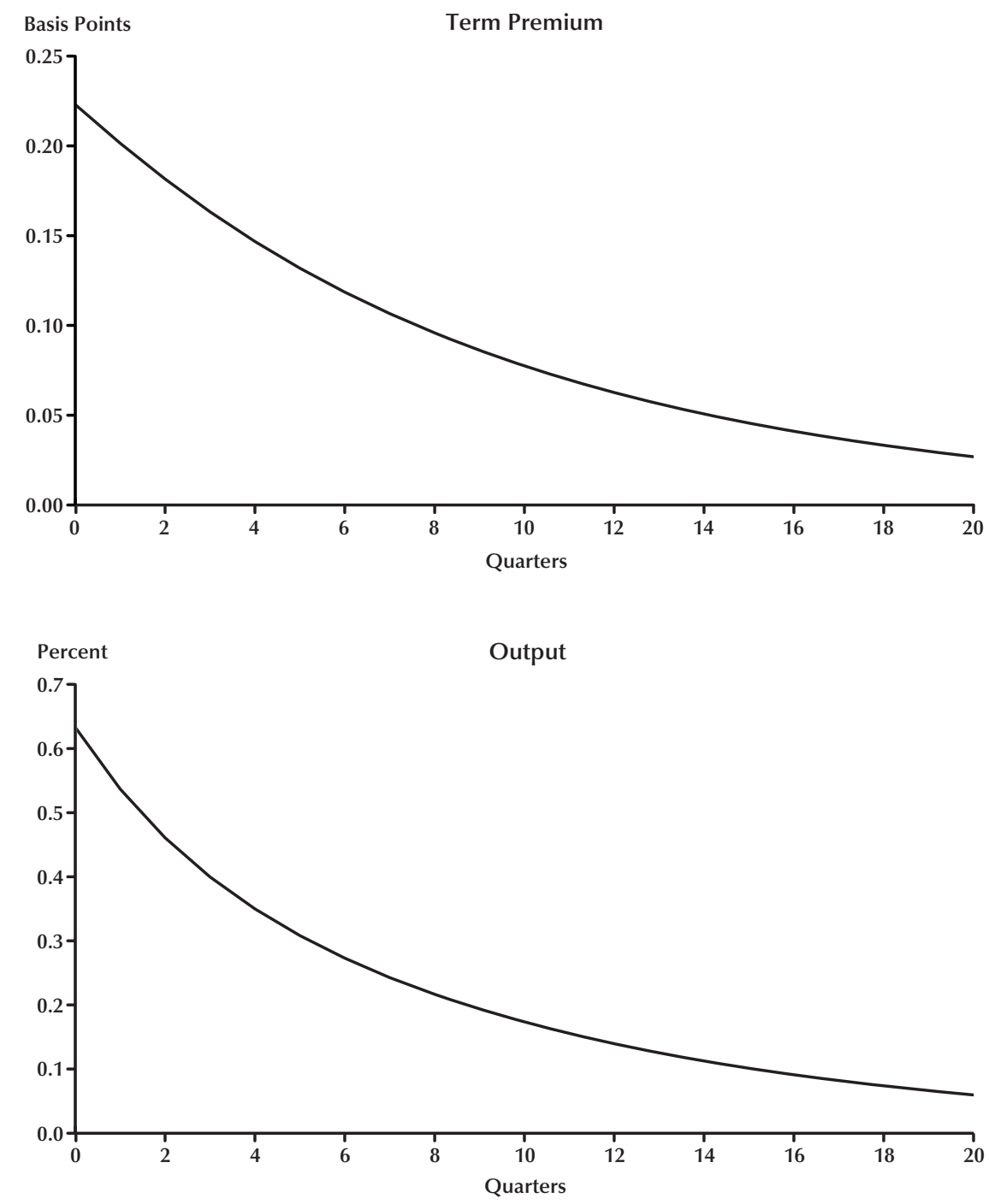
one of the primary limitations of the structural approach to modeling term premiums, which we will discuss in more detail below.

Finally, we note that, although this structural model is very simple, in principle there is no reason why the same analysis cannot be performed using larger and more realistic DSGE models, such as Smets and Wouters (2003), Christiano, Eichenbaum, and Evans (2005), or the extensions of these in use at a number of central banks and international policy institutions. ${ }^{9}$ Even with these larger models, we can describe the term-premium response to any given structural shock and the broader implications of the shock for the economy and optimal monetary policy.

\section{Limitations of the DSGE Model of the Term Premium}

Using a structural DSGE model to investigate the relationship between the term premium and the economy has advantages in terms of conceptual clarity, but there are also a number of limitations that prevent the structural-modeling approach from being useful at present as an empirical workhorse for studying the term premium. This remains true despite the increasing use of structural macroeconomic models at policymaking institutions for the study of other macroeconomic variables, such as output and inflation. These limitations generally fall into two categories: theoretical uncertainties and computational intractabilities.

Regarding the former, even though some DSGE models—sometimes crucially augmented with highly persistent structural shocks-appear to match the empirical impulse responses of macroeconomic variables, such as output and inflation, researchers do not agree on how to specify these models to match asset prices. For example, a variety of proposals to explain the equity-premium puzzle include habit formation

\footnotetext{
9 Some notable extensions include Altig et al. (2005) to the case of firm-specific capital, Adolfson et al. (2007) to the case of a small open economy, and Pesenti (2002) and Erceg, Guerrieri, and Gust (2006) to a large-scale (several hundred equations) multicountryblock context for use at the International Monetary Fund and the Federal Reserve Board, respectively.
}

in consumption (Campbell and Cochrane, 1999), time-inseparable preferences (Epstein and Zin, 1989), and heterogeneous agents (Constantinides and Duffie, 1996, and Alvarez and Jermann, 2001). This lack of consensus implies that there is much uncertainty about the appropriate DSGE specification for analyzing the term premium.

The possibility that a heterogeneous-agent model is necessary to understand risk premiums poses perhaps the most daunting challenge for structural modelers of the term premium. In the case of heterogeneous agents with limited participation in financial markets, different households' valuations of state-contingent claims are not equalized, so determining equilibrium asset prices can become much more complicated than in the representative-household case. Although a stochastic discount factor still exists under weak assumptions even in the heterogeneous-household case, it need not conform to the typical utility functions that are in use in current structural macroeconomic models. ${ }^{10}$

The structural approach to asset pricing also faces substantial computational challenges, particularly for the larger-scale models that are becoming popular for the analysis of macroeconomic variables. Closed-form solutions do not exist in general, and full numerical solutions are computationally intractable except for the simplest possible models. ${ }^{11}$ The standard approach of log-linearization around a steady state that has proved so useful in macroeconomics is unfortunately not applicable to asset pricing, because by construction it eliminates all risk premiums in the model. Some extensions of this procedure to a hybrid log-linear log-normal approximation (Wu, 2006, and Bekaert, Cho, and Moreno, 2005)

\footnotetext{
${ }^{10}$ One might even question the assumptions required for a stochastic discount factor to exist. For example, if there are large traders and some financial markets are thin, then it is no longer the case that all investors can purchase any amount of a security at a constant price, contrary to the standard assumptions.

${ }^{11}$ See Backus, Gregory, and Zin (1989), Donaldson, Johnsen, and Mehra (1990), Den Haan (1995), and Chapman (1997) for examples of numerical solutions for bond prices in very simple real business cycle models. Gallmeyer, Hollifield, and Zin (2005) provide a closed-form solution for bond prices in a simple New Keynesian model, under the assumption of a very special reaction function for monetary policy.
} 
and to a full second-order approximation around the steady state (Hördahl, Tristani, and Vestin, 2006b) are only moderately more successful, because they imply that all risk premiums in the model are constant (in other words, these authors all assume the weak form of the expectations hypothesis). Obtaining a local approximation that actually produces time-varying risk or term premiums requires a full third-order approximation, as in our analysis above and in Ravenna and Seppälä (2006). Even then, the implied time variation in the term premium is very small, due to the inherently small size of third-order terms, unless one is willing to assume very large values for the curvature of agents' utility functions, very large stochastic shock variances, and/or very high degrees of habit persistence (which goes back to the theoretical limitations discussed above). Thus, the challenges in computing the asset-pricing implications of DSGE models, while becoming less daunting over time, remain quite substantial.

\section{MACRO-FINANCE MODELS OF THE TERM PREMIUM}

Because of the significant limitations in applying the structural model discussed above, researchers interested in modeling the term premium in a way that can be taken to the data have had no choice but to pursue a less-structural approach. Although one can model "yields with yields" using a completely reduced-form, latentfactor, no-arbitrage asset-pricing model, as in Duffie and Kan (1996) and Dai and Singleton (2000), recent research has focused increasingly on hybrid macro-finance models of the term structure, in which some connections between macroeconomic variables and risk premiums are drawn, albeit not within the framework of a fully structural DSGE model (see Diebold, Piazzesi, and Rudebusch, 2005). The approaches employed in this macro-finance literature have generally fallen into two categories: vector autoregression (VAR) macro-finance models and New Keynesian macrofinance models. We consider each in turn.

\section{VAR-Based Macro-Finance Models}

The first paper in the no-arbitrage macrofinance literature was Ang and Piazzesi (2003). ${ }^{12}$ They assume that the economy follows a VAR:

$$
X_{t}=\mu+\Phi X_{t-1}+\Sigma \varepsilon_{t},
$$

where the state vector, $X_{t}$, contains output, inflation, the one-period nominal interest rate, and two latent factors (discussed below). The stochastic shock, $\varepsilon_{t}$, is i.i.d. over time. In this model, the oneperiod nominal interest rate, $i_{t}$, is determined by a Taylor-type monetary policy rule based on $X_{t}$, so that the model-implied expected path of the short-term interest rate is known at any point in time.

The VAR, however, does not contain any information about the stochastic discount factor. Ang and Piazzesi simply assume that the stochastic discount factor falls into the essentially affine class, as in standard latent-factor finance models, so it has the functional form

$$
m_{t+1}=\exp \left(-i_{t}-\frac{1}{2} \lambda_{t}^{\prime} \lambda_{t}-\lambda_{t}^{\prime} \varepsilon_{t+1}\right),
$$

where $\varepsilon_{t}$ is assumed to be conditionally lognormally distributed and the prices of risk, $\lambda_{t}$, are assumed to be affine in the state vector, $X_{t}$ :

$$
\lambda_{t}=\lambda_{0}+\lambda_{1} X_{t}
$$

Estimation of this model is complicated by the inclusion of two unobserved, latent factors in the state vector, $X_{t}$, which are typical of noarbitrage models in the finance literature. To make estimation tractable, Ang and Piazzesi impose the restriction that the unobserved factors do not interact at all with the observed macroeconomic variables (output and inflation) in the VAR. Because of this very strong restriction, the macro-

\footnotetext{
${ }^{12}$ A number of papers before Ang and Piazzesi (2003) investigated the dynamic interactions between yields and macroeconomic variables in the context of unrestricted VARs, including Evans and Marshall (2001) and Kozicki and Tinsley (2001). Diebold, Rudebusch, and Aruoba (2006) and Kozicki and Tinsley (2005) provide follow-up analysis. As with the no-arbitrage papers discussed below, however, none of these papers has explored whether the term premium implied by their models feeds back to the macroeconomy, the question of interest in the present paper.
} 
economic variables in the model are determined by a VAR that essentially excludes all interest rates (both short-term and long-term rates). Thus, while the Ang-Piazzesi model can effectively capture the extent to which changes in macroeconomic conditions affect the term premium, it cannot capture any aspects of that relationship running in the reverse direction. ${ }^{13}$ In this regard, their model falls short of addressing the topic of interest in the present paper. ${ }^{14}$

Bernanke, Reinhart, and Sack (2004, denoted BRS), employ a similar model but assume that the state vector, $X_{t}$, consists entirely of observable macroeconomic variables, which determine both short-rate expectations (through the VAR) and the prices of risk (15). By eliminating the use of latent variables, the empirical implementation of the model is simplified tremendously. Of course, as in Ang and Piazzesi, the BRS framework will capture effects of movements in the term premium driven by observable factors included in the VAR, but it does not empirically separate the role of the term premium from that of lagged macroeconomic variables. Note that the BRS specification, as in the Ang and Piazzesi model, does not include longer-term interest rates in the VAR (but in this case does include the short-term interest rate), implying that movements in the term premium not captured by the included variables are assumed to have no effect on the dynamics of the economy.

\footnotetext{
${ }^{13}$ Even when movements in the term premium are driven by the observed macroeconomic variables (output and inflation) rather than the latent factors, the Ang-Piazzesi model fails to identify effects of the term premium on the macroeconomy. For example, suppose higher inflation is estimated to raise the term premium and lead to slower growth in the future. We cannot ascribe the slower growth to the term premium, because the higher inflation may also predict tighter monetary policy or other factors that would be expected to slow the economy. Note that the VAR does at least partially address the issue that not all movements in the term premium are created equal, because the predictive power of a change in the term premium will depend on the specific combination of economic factors driving it.

${ }^{14}$ Cochrane and Piazzesi (2006) also focus on the interaction between macroeconomic conditions and the term premium. They use the predictable component of the ex post returns from holding longerterm securities as a measure of the term premium. Their findings support the case that the term premium varies importantly over time, and they link those movements to macroeconomic conditions. However, they do not address whether the term premium itself affects economic activity.
}

Ang, Piazzesi, and Wei (2006, denoted APW), also estimate a no-arbitrage macro-finance model based on a VAR of observed state variables. However, in contrast to BRS, APW explicitly include the five-year Treasury yield as an element of the state vector. Thus, to a very limited extent, their model begins to address the types of effects that are the focus of the present paper. However, their VAR does not distinguish between the riskneutral and term-premium components of the five-year yield, so it is only able to capture distinct effects from these two components if they are correlated (in different ways) with the other variables in the VAR (which are, specifically, the short-term interest rate and GDP growth). Even then, it would not be possible in their model to disentangle the direct effects of the short-term interest rate and GDP growth on future output from the indirect effects that changes in those variables have on the term premium; it is in this respect that the APW model cannot help answer the question we are interested in, even though it allows a separate role for longer-term yields in the VAR. ${ }^{15}$

Finally, Dewachter and Lyrio (2006a,b) consider a model that is very similar in spirit to APW and BRS, only they work in continuous time and allow for a time-varying long-run inflation objective of the central bank, as argued for by Kozicki and Tinsley (2001) and Gürkaynak, Sack, and Swanson (2005). However, just as with the other papers discussed above, Dewachter and Lyrio do not allow changes in the term premium to feed back to the macroeconomic variables of the model.

\section{New Keynesian Macro-Finance Models}

A separate strand of the macro-finance literature has attempted to bridge the gulf between DSGE models and VAR-based macro-finance models by incorporating more economic structure into the latter. Specifically, these papers replace the reduced-form VAR in the macro-finance models with a structural New Keynesian macro-

\footnotetext{
${ }^{15}$ APW also present some related reduced-form results on the forecasting power of the term premium for future GDP growth, which we discuss in more detail in the next section.
} 
economic model that governs the dynamics of the macroeconomic variables.

An early and representative paper in this literature was written by Hördahl, Tristani, and Vestin (2006a, denoted HTV). They begin with a basic New Keynesian structural model in which output, inflation, and the short-term nominal interest rate are governed by the equations

$$
y_{t}=\mu_{y} E_{t} y_{t+1}+\left(1-\mu_{y}\right) y_{t-1}-\zeta_{i}\left(i_{t}-E_{t} \pi_{t+1}\right)+\varepsilon_{t}^{y},
$$

$$
\pi_{t}=\mu_{\pi} E_{t} \pi_{t+1}+\left(1-\mu_{\pi}\right) \pi_{t-1}+\delta_{y} y_{t}-\varepsilon_{t}^{\pi},
$$

$$
i_{t}=\rho_{i} i_{t-1}+\left(1-\rho_{i}\right)\left[g_{\pi}\left(E_{t} \pi_{t+1}-\pi_{t}^{*}\right)+g_{y} y_{t}\right]+\varepsilon_{t}^{i} .
$$

Equation (16) describes a New Keynesian curve that allows for some degree of habit formation on the part of households through the lagged output term; equation (17) describes a New Keynesian Phillips curve that allows for some rule-of-thumb price setters through the lagged inflation term; and equation (18) describes the monetary authority's Taylor-type short-term interest rate reaction function. Equations (16) and (17) are structural in the sense that they can be derived from a loglinearization of household and firm optimality conditions in a simple structural New Keynesian DSGE model along the lines of our benchmark model (although HTV modify this structure by allowing the long-run inflation objective, $\pi_{t}^{*}$, to vary over time).

In contrast to a DSGE asset-pricing model, however, HTV model the term premium using an ad hoc affine structure for the stochastic discount factor, as in the VAR-based models above. Although this approach is not completely structural, it makes the model computationally tractable and provides a good fit to the data while allowing the term premium to vary over time in a manner determined by macroeconomic conditions that are determined structurally (to first order). The true appeal of this type of model is that it is parsimonious and simple while allowing for expectations to influence macroeconomic dynamics and for the term premium to vary nontrivially to macroeconomic developments.

However, as was the case in the VAR-based models, the HTV model does not allow the term premium to feed back to macroeconomic variables. As discussed in the introduction, the structure of the IS curve in the HTV model assumes that economic activity depends only on expectations of the short-term real interest rate and not on the term premium. Thus, this approach is also unable to address the issue considered in the current paper.

RW develop a New Keynesian macro-finance model that comes a step closer to addressing the topic of this paper by allowing for feedback from the term structure to the macroeconomic variables of the model. In particular, RW incorporate two latent term-structure factors into the model and give those latent factors macroeconomic interpretations, with a level factor that is tied to the long-run inflation objective of the central bank and a slope factor that is tied to the cyclical stance of monetary policy. Thus, the latent factors in the RW model can affect economic activity, and the term structure does provide information about the current values of those latent factors. However, RW make no effort to decompose the effects of long-term interest rates on the economy into an expectations component and a term-premium component, so there is no sense in which the term premium itself affects macroeconomic variables.

Wu (2006) and Bekaert, Cho, and Moreno (2005) come closer to a true structural New Keynesian macro-finance model by deriving the stochastic discount factor directly from the utility function of the representative household in the underlying structural model. Thus, like a DSGE model, their papers impose the cross-equation restrictions between the macroeconomy and the stochastic pricing kernel that are ignored when the kernel is specified in an ad hoc affine manner. However, these analyses also suffer from the computational limitations of working within the DSGE framework (discussed above), because both papers are unable to solve the model as specified. 
Instead, those authors use a log-linear, log-normal approximation, which implies that the term premium in the model is time-invariant. ${ }^{16}$ Thus, their papers do not address the question we have posed in this paper. ${ }^{17}$

\section{REDUCED-FORM EVIDENCE ON THE EFFECTS OF THE TERM PREMIUM}

Because of the limitations discussed above, the models in the previous two sections do not provide us with much insight into the empirical economic implications of changes in the term premium. The benchmark structural model is largely unable to reproduce the magnitude and variation of the term premium that is observed in the bond market, and, although the macrofinance models are more successful at capturing the observed behavior of term premiums, they typically impose very restrictive assumptions that eliminate any macroeconomic implications of changes in term premiums. A separate literature that has provided a direct examination of these implications is based on reduced-form empirical evidence. Specifically, in the large literature that uses the slope of the yield curve to forecast subsequent GDP growth, several recent papers have tried to estimate separately the predictive power of the term premium. In this section, we summarize these papers and contribute some new evidence on this issue.

An important caveat worth repeating is that there is only a reduced-form relationship—not a structural one-between the term premium and future output growth, so even the sign of their pair-

\footnotetext{
${ }^{16}$ Indeed, the term premium would be zero except for the fact that Wu (2006) and Bekaert, Cho, and Moreno (2005) allow some secondand higher-order terms to remain in these models. In particular, they leave the log-normality of the stochastic pricing kernel in its nonlinear form, which implies a nonzero, albeit constant, risk premium. A drawback of this approach is that it treats some secondorder terms as important, while dropping other terms of similar magnitude.

${ }^{17}$ A related paper by Gallmeyer, Hollifield, and Zin (2005) provides a full nonlinear solution to a very similar model. However, they are able to solve the model only under the assumption of an extremely special reaction function for monetary policy; thus, their method has no generality and is invalid in cases in which that policy reaction function is not precisely followed.
}

wise correlation over a given sample will depend on which types of shocks are most influential. Nevertheless, it may be of interest to consider the average correlation between future output growth and changes in the term premium over some recent history. If the mixture of shocks is expected to remain relatively stable, then the average estimated reduced-form relationship between the term premium and future economic growth could be useful for forecasting. For this reason, the historical relationship may provide useful information to a policymaker who has to decide whether and how to respond to a given change in the term premium.

\section{Evidence in the Literature}

Recent research relating the term premium to subsequent GDP growth has been part of a much larger literature on the predictive power of the slope of the yield curve. A common approach in this literature is to investigate whether the spread between short-term and long-term interest rates has significant predictive power for future GDP growth by estimating a regression of the form

$$
y_{t+4}-y_{t}=\beta_{0}+\beta_{1}\left(y_{t}-y_{t-4}\right)+\beta_{2}\left(i_{t}^{(n)}-i_{t}\right)+\varepsilon_{t},
$$

where $y_{t}$ is the log of real GDP at time $t$ and $i_{t}^{(n)}$ is the $n$-quarter interest rate (usually a longer-term rate such as the 10-year Treasury yield). ${ }^{18}$ The standard finding is that the estimated coefficient $\beta_{2}$ is significant and positive, indicating that the yield-curve slope helps predict growth.

Note that equation (19) is a reduced-form specification that has no economic structure. However, it can be motivated by thinking of the long-term interest rate as a proxy for the neutral level of the nominal funds rate, so that the yieldcurve slope captures the current stance of monetary policy relative to its long-run level. For example, a steep yield-curve slope (with short rates unusually low relative to long rates) would indicate that policy is accommodative and would

\footnotetext{
${ }^{18}$ This equation assumes that the dependent variable is future GDP growth (a continuous variable). Other papers in this literature use a dummy variable for recessions (a discrete variable). In either case, the motivation for the approach is the same and the results are qualitatively similar.
} 
be associated with faster subsequent growth, thus accounting for the positive coefficient.

In this respect, the use of the long-term interest rate in the regression (19) is motivated entirely by the component related to the expected longrun level of the short rate. But the long-term rate also includes a term premium; hence, any variation in this premium will affect the performance of the equation. Indeed, it is useful to decompose the yield-curve slope into these two components, as follows:

$$
i_{t}^{(n)}-i_{t}=\left(\frac{1}{n} \sum_{j=0}^{n-1} E_{t} i_{t+j}-i_{t}\right)+\left(i_{t}^{(n)}-\frac{1}{n} \sum_{j=0}^{n-1} E_{t} i_{t+j}\right) .
$$

The first term captures the expectations component, or the proximity of the short rate to its expected long-run level. The second component is the term premium, or the amount by which the long rate exceeds the expected return from investing in a series of short-term instruments. For notational simplicity, we will denote the first component in (20) as exsp $p_{t}$, the expected-rate component of the yield spread, and the second component as $t p_{t}$, the term premium.

With this decomposition, the prediction equation (19) can be generalized as follows:

$$
y_{t+4}-y_{t}=\beta_{0}+\beta_{1}\left(y_{t}-y_{t-4}\right)+\beta_{2} \operatorname{exsp}_{t}+\beta_{3} t p_{t}+\varepsilon_{t} .
$$

The standard equation (19) imposes the coefficient restriction $\beta_{2}=\beta_{3}$. Loosening that restriction allows the term premium to have a different implication for subsequent growth than the expected-rate component. ${ }^{19}$ Several recent papers have considered this issue, as we will briefly summarize.

The first paper to examine the importance of the above decomposition for forecasting was

\footnotetext{
${ }^{19}$ Because this equation is intended to capture the effects on output from changes in interest rates, it is not far removed from the literature on estimating IS curves. Most empirical implementations of the IS curve, however, assume that output is related to short-term interest rates rather than long-term interest rates. Or, as seen in Fuhrer and Rudebusch (2004), these papers focus on the component of long rates tied to short-rate expectations, following the New Keynesian output equation very closely. As a result, even this literature is more closely tied to estimating the parameter $\beta_{2}$ than the parameter $\beta_{3}$.
}

Hamilton and Kim (2002), which forecasts future GDP growth using a spread between the 10-year and 3-month Treasury yields in equation (19). The innovation of their paper is that it then separates the yield spread into the expectations and termpremium components considered in equation (21). The authors achieve this separation by considering the ex post realizations of short rates, using instruments known ex ante to isolate the expectations component. They find that the coefficients $\beta_{2}$ and $\beta_{3}$ are indeed statistically significantly different from one another, although both coefficients are estimated to be positive. Note that a positive value for $\beta_{3}$ implies that a decline in the term premium is associated with slower future growth.

A second paper that decomposes the predictive power of the yield spread into its expectations and term-premium components is Favero,

Kaminska, and Söderström (2005). These authors differ from Hamilton and Kim (2002) by using a real-time VAR to compute short-rate expectations rather than a regression of ex post realizations of short rates on ex ante instruments. As in Hamilton and Kim (2002), they find a positive sign for the coefficient $\beta_{3}$, so that a lower term premium again predicts slower GDP growth.

A third relevant paper is by Wright (2006), who touches on this issue in the context of a probit model for forecasting recessions. Wright considers the predictive power of the yield slope, and then he investigates whether the return forecasting factor from Cochrane and Piazzesi (2005) also enters those regressions significantly. Since this factor is correlated with the term premium, he is implicitly controlling for the term premium, as in equation (21). He finds that this factor is insignificant for predicting recessions over horizons of two or four quarters but has a significant negative coefficient for predicting recessions over a six-quarter horizon; that is, a lower term premium raises the odds of a recession, consistent with the findings of the other papers that it would predict slower growth.

A final reference is APW. As noted above, they use a VAR that includes long rates, GDP growth, and a short rate, but they cannot separate out the effects of the term premium from other 
movements in long-term interest rates. However, the authors perform an additional exercise in which they calculate the expected-rate and termpremium components of the long rate as implied by the VAR and then estimate the forecasting equation (21), allowing for different effects from these two components. In contrast to the previously discussed papers, APW find that the term premium has no predictive power for future GDP growth; that is, the coefficient $\beta_{3}$ is zero.

Overall, the handful of papers that have directly tackled the predictive power of the term premium have produced results that starkly contrast with the intuition that Chairman Bernanke expressed in his March 2006 speech (see the introduction). The empirical studies to date suggest that, if anything, the relationship has the opposite sign from the practitioner view. According to these results, policymakers had no basis for worrying that the decline in the term premium might be stimulating the economy and instead should have worried that it was a precursor to lower GDP growth.

\section{Empirical Estimates of the Term Premium}

Estimation of equation (21) requires a measure of the term premium, and there are a variety of possibilities in the literature. We begin our empirical analysis by collecting a number of the prominent term-premium measures and examining some of the similarities and differences among them.

Specifically, we consider five measures of the term premium on a zero-coupon nominal 10year Treasury security ${ }^{20}$ :

1. VAR measure: The first of these measures, which we label the "VAR" measure, is based on a straightforward projection of the short rate from a simple but standard three-

\footnotetext{
${ }^{20}$ Note that some of these term-premium measures are adjusted for convexity (e.g., Kim-Wright, Bernanke-Reinhart-Sack, and Rudebusch-Wu), and some are not (e.g., our VAR-based measure and our extension of the Cochrane-Piazzesi measure). The adjustment for convexity has little or no impact on our results, however; for example, the correlation between the VAR-based term-premium measure and the Kim-Wright and Bernanke-Reinhart-Sack measures are 0.94 and 0.96 , respectively.
}

variable macroeconomic VAR comprising four lags each of the unemployment rate, quarterly inflation in the consumer price index, and the 3-month Treasury bill rate. At each date the VAR can be used to forecast the short rate over a given horizon, and the average expected future short rate can be used as an estimate of the risk-neutral long-term rate of that maturity. ${ }^{21}$ The difference between the observed long-term rate and the risk-neutral long-term rate then provides a simple estimate of the term premium. This approach has been used by Evans and Marshall (2001), Favero, Kaminska, and Söderström (2005), Diebold, Rudebusch, and Aruoba (2006), and Cochrane and Piazzesi (2006).

2. Bernanke-Reinhart-Sack measure: A potential shortcoming of using a VAR to estimate the term premium is that it does not impose any consistency between the yield curve at a given point in time and the VAR's projected evolution of those yields. Such pricing consistency can be imposed by using a no-arbitrage model of the term structure. As discussed in the previous section, a noarbitrage structure can be laid on top of a VAR to estimate the behavior of the term premium, as in BRS. Here, we consider the term-premium estimate from that paper, as updated by Rudebusch, Swanson, and $\mathrm{Wu}$ (2006).

\section{Rudebusch-Wu measure: No-arbitrage} restrictions can also be imposed on top of a New Keynesian macroeconomic model. Here we take the term premium estimated from one such model, Rudebusch and $\mathrm{Wu}$ (2003 and 2007), discussed earlier. As with the Bernanke-Reinhart-Sack measure, this term-premium measure was extended to a

\footnotetext{
${ }^{21}$ Of course, there are several reasons for not taking these VAR projections too seriously as good measures of the actual interest rate expectations of bond traders at the time. Rudebusch (1998) describes three important limitations of such VAR representations: (i) the use of a time-invariant, linear structure, (ii) the use of final revised data and full-sample estimates, and (iii) the limited number of information variables. We examined several rolling-sample estimated VARs as well and obtained similar results.
} 
longer sample by Rudebusch, Swanson, and $\mathrm{Wu}$ (2006), and we use this extended version below.

4. Kim-Wright measure: One can also estimate the term premium using a standard noarbitrage dynamic latent-factor model from finance (with no macroeconomic structure underlying the factors). In these models, risk-neutral yields and the term premium are determined by latent factors that are themselves linear functions of the observed bond-yield data. We use the term-premium measure from a three-factor model discussed by Kim and Wright (2005), which we extend back to $1961 .^{22}$

5. Cochrane-Piazzesi measure: Cochrane and Piazzesi (2005) analyze excess returns for a range of securities over a one-year holding period. Their primary finding is that a single factor-a particular combination of current forward rates-predicts a considerable portion of the excess returns from a one-year holding period for Treasury securities. For our purposes, however, we are interested in the term premium on a 10-year security, or the (annualized) excess return expected over the 10-year period. Sack (2006a) provides a straightforward approach for converting the CochranePiazzesi one-year holding-period results into a measure of the term premium. Specifically, the expected one-period excess returns implied by the Cochrane-Piazzesi estimates, together with the one-year riskfree rate, imply an expected set of zerocoupon yields one year ahead (because the only way to generate expected returns on zero-coupon securities is through changes

${ }^{22}$ We extend the Kim-Wright measure back to 1961 by regressing the three Kim-Wright latent factors on the first three principal components of the yield curve and using these coefficients to estimate the Kim-Wright factors in prior years. Because the term premium in the model is a linear function of observed yields, and because the Kim-Wright model fits the yield-curve data very well, this exercise should come very close to deriving the same factors that would be implied if we extended their model back to 1961. Over the period where our proxy and the actual Kim-Wright term premium overlap, the correlation between the two measures is 0.998 and the average absolute difference between them is less than 4 basis points. in yield). Those expected future yields can then be used to compute the expected Cochrane-Piazzesi factor one year ahead and, hence, the expected excess returns over the one-year period beginning one year ahead. By iterating forward, one can compute the expected excess return for each of the next 10 years, thereby yielding a measure of the term premium on the 10year security.

As is clear from the above descriptions, the approaches used to derive the five term-premium measures differ considerably in the variables included and the theoretical restrictions incorporated. Nevertheless, the measures show many similar movements over time, as can be seen in Figure 4, which plots the five measures of the term premium for the 10-year zero-coupon Treasury yield back to 1984 .

Three of the measures, in particular-the VAR, Bernanke-Reinhart-Sack, and Kim-Wright-are remarkably highly correlated over this period. ${ }^{23}$ As shown in Table 1, the correlation coefficients among these measures range from 0.94 to 0.98 . The other two measures-Rudebusch-Wu and Cochrane-Piazzesi-are less correlated with the others. For example, the correlation coefficients with the VAR measure are 0.68 for Rudebusch$\mathrm{Wu}$ and 0.88 for Cochrane-Piazzesi. These lower correlations largely reflect that the Rudebusch$\mathrm{Wu}$ measure is more stable than the others and that the Cochrane-Piazzesi measure is more volatile.

The greater stability of the Rudebusch-Wu measure can be easily understood. Their underlying model attributes much of the variation in the 10-year Treasury yield to changes in the expected future path of short rates, reflecting, in their framework, variation in the perceived inflation target of the central bank. That assumption is supported by other research. For example, Gürkaynak, Sack, and Swanson (2005) found significant systematic variation in far-ahead for-

\footnotetext{
23 These correlations are very high in comparison with, say, the zero correlations exhibited by various authors' measures of monetary policy shocks, as noted in Rudebusch (1998).
} 


\section{Figure 4}

\section{Five Measures of the 10-Year Term Premium}

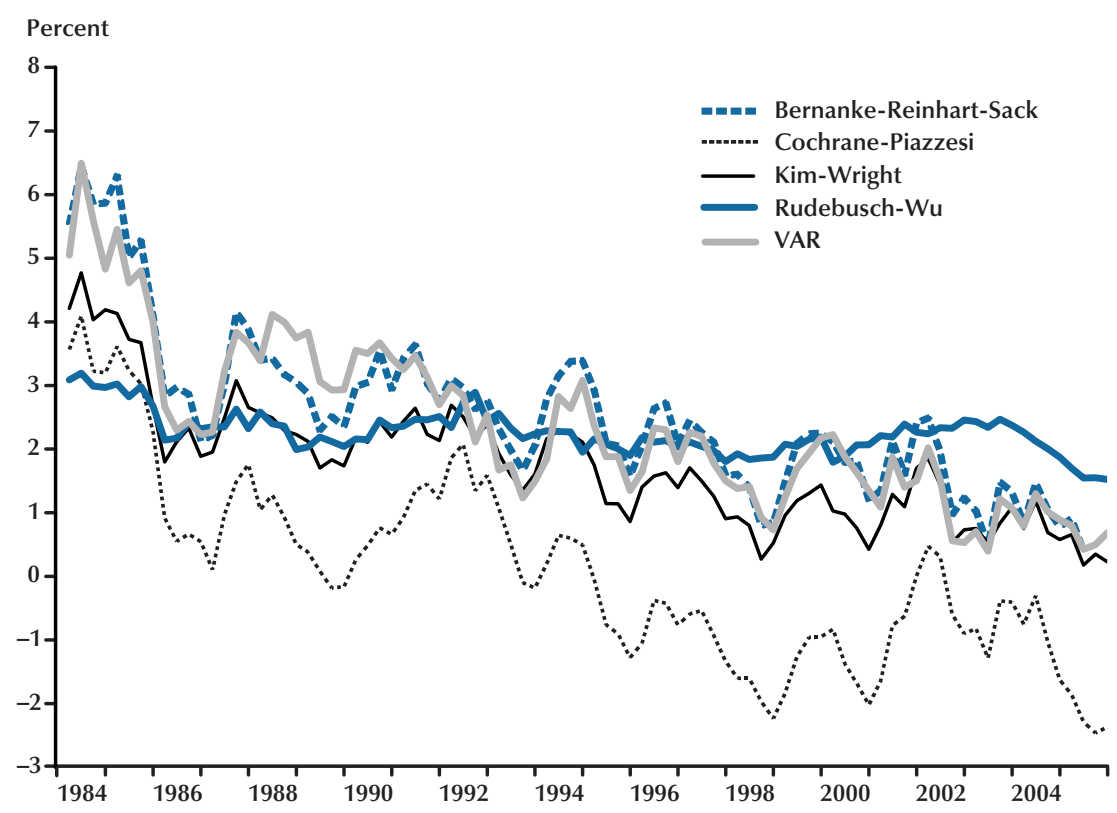

\section{Table 1}

Correlations Among the Five Measures of the Term Premium

\begin{tabular}{llllll} 
& BRS & RW & KW & CP & \\
\hline BRS & 1.00 & & & & \\
RW & 0.76 & 1.00 & 1.00 & & \\
KW & 0.98 & 0.81 & 0.96 & 1.00 & \\
CP & 0.92 & 0.87 & 0.94 & 0.88 & 1.00
\end{tabular}

ward nominal interest rates in response to macroeconomic news in a way that suggested changes in inflation expectations rather than changes in term premiums. Similarly, Kozicki and Tinsley (2001) found that statistical models that allow for a "moving endpoint" are able to fit interest rate and inflation time series much better than standard stationary or difference-stationary VARs. By attributing more of the movement in long rates to short-rate expectations, the Rudebusch-Wu analysis does not need as much variation in the term premium to explain the observed variation in yields. ${ }^{24}$

The behavior of the measure based on Cochrane and Piazzesi (2005) is harder to understand. This measure is well below the other meas-

${ }^{24}$ One could argue that a weakness of the other term-premium estimates is that they are based on models that assume that the longrun features of the economy, such as the steady-state real interest rate and rate of inflation, are completely anchored. 


\section{Figure 5}

\section{Kim-Wright Decomposition of the 10-Year Zero-Coupon Yield}

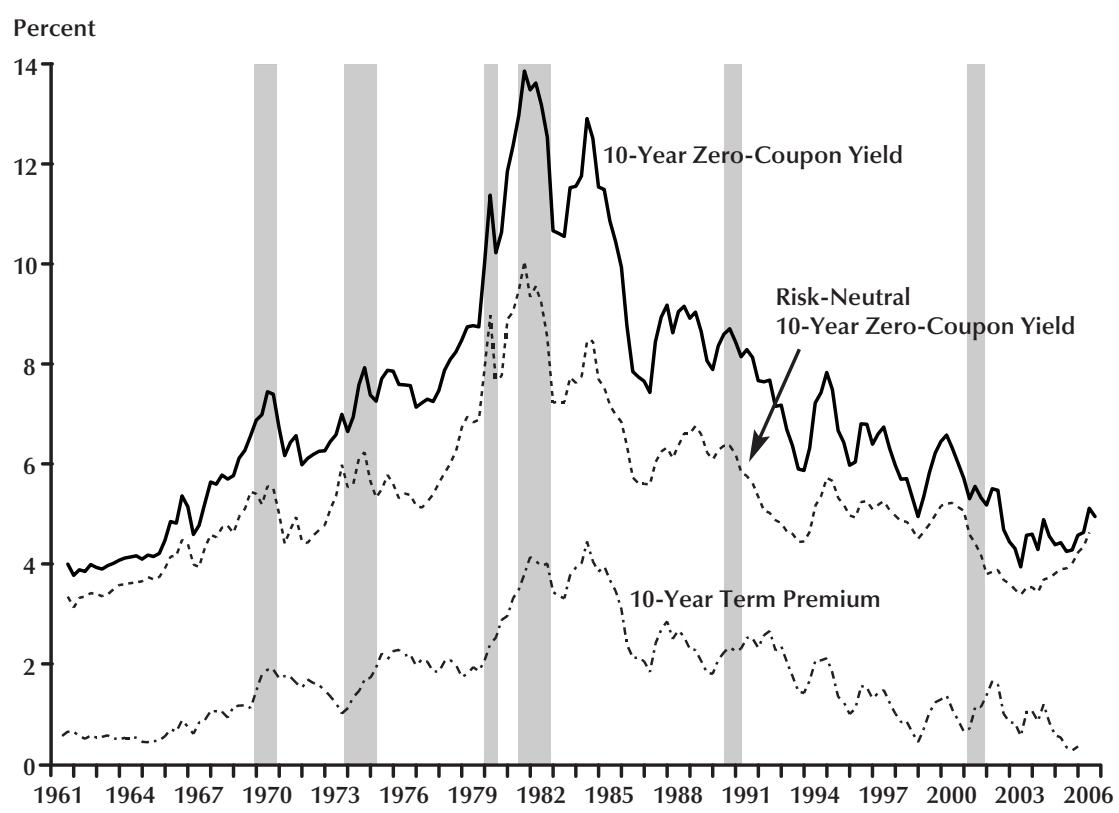

NOTE: The shaded bars indicate recessions as dated by the National Bureau of Economic Research.

ures and is much more volatile. To a large extent, this behavior simply mimics the one-period expected excess returns computed by Cochrane and Piazzesi. Indeed, Sack (2006b) and Wright (2006) have pointed out that the implied oneperiod expected excess returns are surprisingly volatile and are currently very negative. This behavior partly shows through to the implied term-premium measure.

Overall, Figure 4 provides us with a menu of choices for the analysis that follows. ${ }^{25}$ Even with the differences noted above, the five measures show considerable similarities in their variation over this sample. Indeed, the first principal component captures 95 percent of the variation in these five term-premium estimates. In the analysis in the next section, we focus our attention on the

${ }^{25}$ In contrast to the measures shown in Figure 4, Ludvigson and Ng (2006) provide one that has considerable high-frequency variation and little persistence or predictive power for economic activity. However, we have some reservations about their identification of the term premium and exclude it from our analysis.
Kim-Wright measure. This measure appears to be representative of the other measures considered. In fact, it is very highly correlated (0.99) with the first principal component of all five measures. Moreover, it has the advantage that it can be extended back to the early 1960s, allowing us to conduct our analysis over a longer sample.

The 10-year zero-coupon yield is shown in Figure 5 along with the two components based on the Kim-Wright term-premium estimate. ${ }^{26}$ As can be seen, both short-rate expectations and the term premium contributed to the run-up in yields through the early 1980s and, since then, to the decline in yields. As noted by Kim and Wright (2005), the term premium recently has fallen to very low levels, a pattern consistent with the

\footnotetext{
${ }^{26}$ The yield data considered here are from the Gürkaynak, Sack, and Wright (2006) database. Those authors do not recommend using the 10-year Treasury yield before 1971, as there are very few maturities at that horizon for estimating the yield curve. However, their 10-year yield is highly correlated with the Treasury constantmaturity 10-year yield over that period, which justified its use. All results that follow are robust to beginning the sample in 1971.
} 


\section{Figure 6}

\section{Kim-Wright Term Premium and the CBO Output Gap}

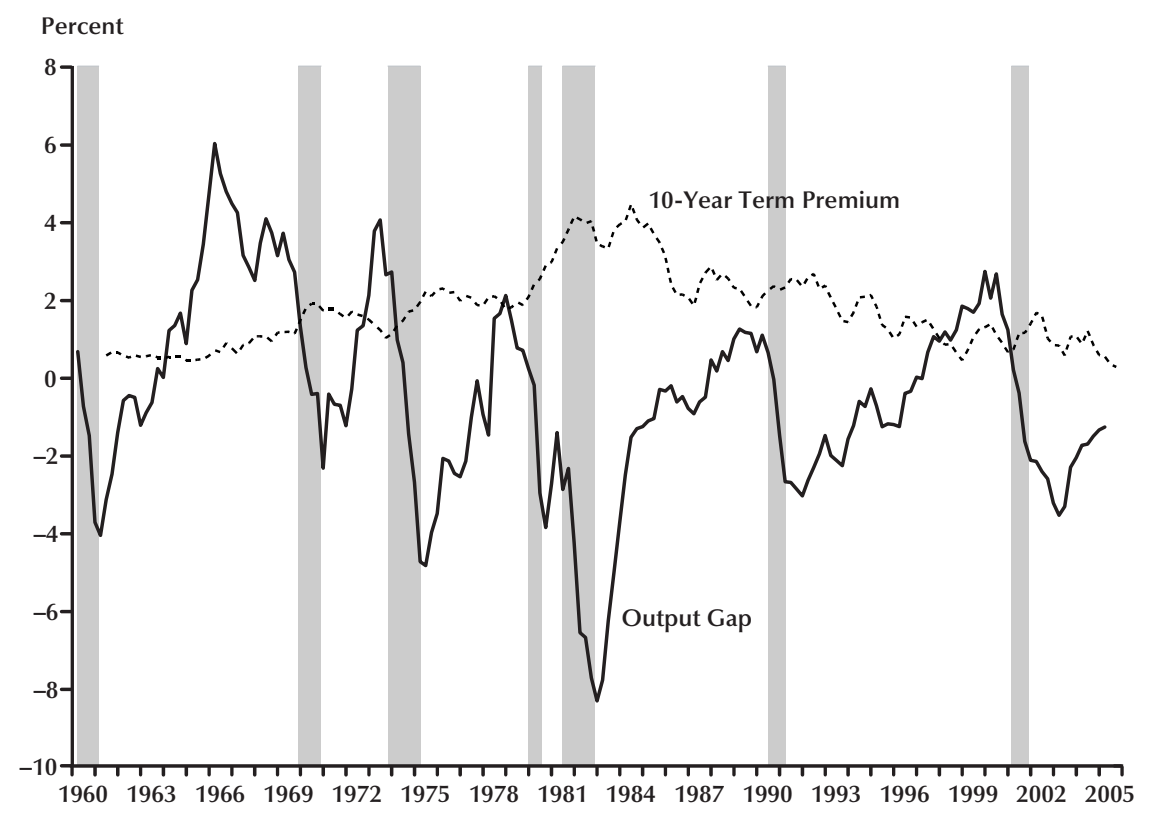

NOTE: The shaded bars indicate recessions as dated by the National Bureau of Economic Research.

conundrum discussed by former Chairman Alan Greenspan.

Figure 6 plots this term-premium measure along with the Congressional Budget Office (CBO) output gap and provides the first hint of a negative relationship between the two. It is this relationship that we now explore in more detail.

\section{New Evidence on the Implications of the Term Premium}

We begin by estimating the standard relationship between the slope of the yield curve and subsequent GDP growth, using the specification in equation (19). The long rate is a 10-year zerocoupon Treasury yield, taken from the Gürkaynak, Sack, and Wright (2006) database. The short rate is the 3-month Treasury bill rate from the Federal Reserve's H.15 data release. All data are quarterly averages, and the sample ranges from 1961:Q3 to 2005:Q4. We examine both this full sample and a shorter subsample beginning in 1984, which arguably has a more consistent monetary policy regime (e.g., Rudebusch and $\mathrm{Wu}, 2007$ ).

Results are presented in the first column of Table 2. Over the full sample, we find that the coefficient for the yield-curve slope is highly statistically significant and has a positive sign. This estimate implies that a flatter yield curve predicts slower GDP growth, the standard finding in the academic literature. Over the shorter sample, the estimated coefficient loses its significance, reflecting another fact that is well-appreciated among researchers - that the predictive power of the yield-curve slope for growth appears to have diminished in recent decades.

As discussed above, this approach is purely a reduced-form exercise that is not explicitly tied to a theoretical structure. However, a common motivation for using the yield-curve slope as a predictor is that it serves as a proxy for the stance of monetary policy relative to its neutral level. Given this motivation, one would prefer to measure the yield-curve slope based strictly on the 


\section{Table 2}

\section{Prediction Equations for GDP Growth Dependent Variable: $y_{t+4}-y_{t}$}

(1)

(2)

\begin{tabular}{ll}
\hline 1962-2005 Sample & \\
$y_{t}-y_{t-4}$ & $0.15(1.57)$ \\
$i_{t}^{(n)}-i_{t}$ & $0.64(3.64)$ \\
$\operatorname{exs}_{t}$ & \\
$\operatorname{exsp}_{t-4}$ & \\
$t p_{t}$ & \\
$t p_{t-4}$ & \\
$\operatorname{exsp}_{t}-\operatorname{exsp}_{t-4}$ & \\
$t p_{t}-t p_{t-4}$ &
\end{tabular}

\section{5-2005 Sample}

$\begin{array}{ll}y_{t}-y_{t-4} & 0.26(2.54) \\ i_{t}^{(n)}-i_{t} & 0.28(1.29) \\ \operatorname{exsp}_{t} & \\ \operatorname{exsp}_{t-4} & \\ t p_{t} & \\ t p_{t-4} & \\ \operatorname{exsp}_{t}-\operatorname{exsp}_{t-4} & \\ t p_{t}-t p_{t-4} & \end{array}$

$0.12(1.18)$

$0.68(4.03)$

$0.30(0.92)$

$0.32(2.31)$

$0.35(1.59)$

$0.07(0.25)$
(3)

(4)

$0.32(3.04) \quad 0.38(4.22)$

$1.03(5.64)$

$-0.79(-3.49)$

$-0.61(-1.34)$

$0.54(1.24)$

$0.96(5.62)$

$-0.77(-1.95)$

$0.36(2.68)$

$0.46(1.92)$

$-0.07(-0.32)$

$-0.46(-1.15)$

$0.61(2.18)$

NOTE: Coefficient estimates are shown with their $t$-statistics in parentheses ( $t$-statistics have been corrected for residual heteroskedasticity and autocorrelation). Each regression includes a constant that is not reported.

portion of the long-term interest rate associated with expectations of the short-term rate. In that context, we can also ask how the other component of the long rate-the term premium-affects growth. This consideration leads to specification (21) above, in which the two components of the yield-curve slope are allowed to have different predictive effects for subsequent GDP growth.

We can implement this approach using the term-premium measure described above. ${ }^{27}$ The results are shown in column 2 . For both samples, the expectations-based component of the yield slope has slightly stronger predictive power than the pure yield-curve slope (that is, the coefficient

\footnotetext{
${ }^{27}$ In our analysis, we ignore any potential issues associated with generated regressors.
}

on this component is slightly larger and more significant than the coefficient on the overall slope reported in column 1), and the coefficient on the term premium, $\beta_{3}$, is not significantly different from zero. However, we are unable to reject the hypothesis that $\beta_{2}=\beta_{3}$ at even the 10 percent level over either the post-1962 or post1985 sample.

Our findings are similar in spirit to the existing empirical evidence that the term premium has a different effect on subsequent growth than the expectations-related component of the yield curve. Note that the only purpose of having a termpremium measure, according to these results, is to determine the expectations component of the yield slope more accurately. The term premium itself has no predictive power for future growth. 
However, the specification of these regression equations seems somewhat at odds with the models we presented earlier. For example, the New Keynesian IS curve (2) could be used to motivate the use of the yield-curve slope, as it assumes that output is determined by the deviation of the real short-term interest rate from its equilibrium level. The expectations component of the yield-curve slope might capture this variable, but it should then be related to the level of the output gap. In contrast, the reduced-form specifications (19) and (21) relate the slope of the yield curve to the growth rate of output. Thus, this specification seems to differ from the more structural models by a derivative. Moreover, the term premium in Figures 5 and 6 appears to be nonstationary or nearly nonstationary, while GDP growth is much closer to being stationary. Thus, from a statistical point of view, specifications (19) and (21) are also highly suspect.

If we difference equation (2) to arrive at a specification in growth rates, it would suggest that it is changes in the stance of monetary policy that predict future GDP growth. ${ }^{28}$ This suggests investigating whether GDP growth is tied to changes in the stance of policy and changes in the term premium, as opposed to the levels of those variables.

As an exploratory step in this direction, we re-estimate equation (21) with an additional oneyear lag of the right-hand-side variables included in the regression. The results, shown in column 3 of Table 2, strongly hint that there is greater predictive power associated with the changes in these variables than with their levels. Indeed, one can reject the hypothesis that the coefficients on the lagged variables are zero (at the 1 percent significance level). Moreover, one cannot reject that the right-hand-side variables enter the regression only as changes. That is, the hypothesis that the coefficients on the lag of these components equal the negative of the coefficients on their current levels cannot be rejected even at the 10 percent

\footnotetext{
${ }^{28}$ Some might argue that the dependent variable here should be the growth of the output gap rather than GDP. As discussed below, we obtained similar results using the change in the CBO output gap as the dependent variable.
}

significance level. A similar (though less striking) pattern is found in the shorter sample.

Because both the theory and the hypothesis tests in the preceding paragraph suggest that only differences should matter, column (4) of the table presents results from estimating the baseline forecasting regression equation in differences, namely,

$$
\begin{aligned}
y_{t+4}-y_{t} & =\beta_{0}+\beta_{1}\left(y_{t}-y_{t-4}\right)+\beta_{2}\left(\operatorname{exsp}_{t}-\operatorname{exsp}_{t-4}\right) \\
& +\beta_{3}\left(t p_{t}-t p_{t-4}\right)+\varepsilon_{t} .
\end{aligned}
$$

The full-sample results indicate that both components of the yield-curve slope matter for future growth. The coefficient on the risk-neutral expectations component of the yield-curve slope is now larger and more statistically significant than in any of the earlier specifications. We can also overwhelmingly reject the hypothesis that $\beta_{2}=\beta_{3}$ (with $p$-values less than $10^{-4}$ ). This finding indicates that GDP growth is expected to be higher not when the short-term interest rate is merely low relative to its long-run level, but when it has fallen relative to that level.

More importantly for this paper, we find that the estimated coefficient on the term premium is now negative and (marginally) statistically significant. According to these results, a decline in the term premium tends to be followed by faster GDP growth—the opposite sign of the relationship uncovered by previous empirical studies. (In the shorter sample, all of the coefficients are again less significant. However, we still reject the hypothesis that $\beta_{2}=\beta_{3}$ [with a $p$-value of 0.0395] in column 4 , and the coefficient on the change in the term premium is again negative and borderline statistically significant. ${ }^{29}$ )

Our findings line up with the intuition expressed by Chairman Bernanke when he suggested that the declining term premium signaled additional stimulus to the economy. Our results

\footnotetext{
${ }^{29}$ Furthermore, using the year-on-year change in the CBO output gap as the predicted variable rather than the year-on-year change in output itself gave similar results. Specifically, the coefficient on the term premium remains negative, with a $p$-value just less than 0.05 . These results suggest that a decline in the term premium predicts a higher future value of the output gap and that policymakers might want to take that prediction into account when formulating the optimal policy response.
} 
are the first piece of evidence (that we are aware of) to support this hypothesis, and they stand in sharp contrast to the previous empirical evidence presented by Hamilton and Kim (2002), Favero, Kaminska, and Söderström (2005), and Wright (2006).

\section{CONCLUSIONS}

Our results can be usefully summarized from the perspective of advising monetary policymakers. Specifically, policymakers may wonder how they should respond when confronted with a substantial change in the term premium, such as the recent decline that appears to have taken place during 2004 and 2005.

The first, and perhaps most important, conclusion from our analysis is that policymakers should always try to determine the source of the change in the term premium. If that source can be identified, then policymakers are advised to consider the repercussions of that underlying driving force more broadly rather than focusing exclusively on the change in the term premium. In this way, policymakers can take into account the macroeconomic implications of the structural shifts or disturbances that are affecting the term premium.

Of course, policymakers often may be uncertain about the reasons for changes in the term premium. Indeed, during the past few years, a variety of only tentative explanations have been offered for the seemingly low term premium. In such a situation, policymakers may find our reduced-form analysis of the implications of the term premium for future economic activity to be a useful baseline. Our results suggest that a decline in the term premium has typically been associated with higher future GDP growth, which appears consistent with the practitioner view. Indeed, according to our reduced-form analysis, the attention that Federal Reserve officials paid to the seemingly large decline in the term premium in 2004 and 2005 may have been justified.

Finally, our finding that changes in the term premium have a significant correlation with future GDP growth is not captured by many macroeco- nomic models. Understanding and incorporating this correlation within the framework of a model would appear to be a useful addition to the research agenda. In this regard, we only speculate that our empirical findings may reflect a heterogeneous population in which a decline in the term premium makes financial market conditions more accommodative for certain classes of borrowers.

\section{REFERENCES}

Adolfson, Malin; Laséen, Stefan; Lindé, Jesper and Villani, Mattias. "Evaluating an Estimated New Keynesian Small Open Economy Model.” Journal of Economic Dynamics and Control, 2007 (forthcoming).

Altig, David; Christiano, Lawrence J.; Eichenbaum, Martin and Lindé, Jesper. "Firm-Specific Capital, Nominal Rigidities, and the Business Cycle." Unpublished manuscript, Northwestern University, 2005.

Alvarez, Fernando and Jermann, Urban. "Quantitative Asset Pricing Implications of Endogenous Solvency Constraints." Review of Financial Studies, Winter 2001, 14(4), pp. 1117-51.

Ang, Andrew and Piazzesi, Monika. "No-Arbitrage Vector Autoregression of Term Structure Dynamics with Macroeconomic and Latent Variables." Journal of Monetary Economics, 2003, 50(4), pp. 745-87.

Ang, Andrew; Piazzesi, Monika and Wei, Min. "What Does the Yield Curve Tell Us about GDP Growth?" Journal of Econometrics, March/April 2006, 131(1/2), pp. 359-403.

Backus, David K.; Gregory, Allan W. and Zin, Stanley E. "Risk Premiums in the Term Structure." Journal of Monetary Economics, November 1989, 24(3), pp. 371-99.

Bekaert, Geert; Cho, Seonghoon and Moreno, Antonio. "New-Keynesian Macroeconomics and the Term Structure." Unpublished manuscript, Columbia Business School, 2005.

Bernanke, Ben S. "Reflections on the Yield Curve and Monetary Policy." Presented at the Economic 
Club of New York, March 20, 2006;

www.federalreserve.gov/boarddocs/speeches/2006/.

Bernanke, Ben S.; Reinhart, Vincent R. and Sack, Brian P. "Monetary Policy Alternatives at the Zero Bound: An Empirical Assessment." Brookings Papers on Economic Activity, 2004, 2, pp. 1-100.

Campbell, John Y. and Cochrane, John H. "By Force of Habit: A Consumption-Based Explanation of Aggregate Stock Market Behavior." Journal of Political Economy, April 1999, 107(2), pp. 205-51.

Chapman, David. "The Cyclical Properties of Consumption Growth and the Real Term Structure." Journal of Monetary Economics, 1997, 39(2), pp. 145-72.

Christiano, Lawrence J.; Eichenbaum, Martin and Evans, Charles L. "Nominal Rigidities and the Dynamic Effects of a Shock to Monetary Policy." Journal of Political Economy, February 2005, 113(1), pp. 1-45.

Cochrane, John H. Asset Pricing. Princeton: Princeton University Press, 2001.

Cochrane, John and Piazzesi, Monika. "Bond Risk Premia." American Economic Review, March 2005, 95(1), pp. 138-60.

Cochrane, John and Piazzesi, Monika. "Decomposing the Yield Curve.” Unpublished manuscript, University of Chicago, 2006.

Constantinides, George and Duffie, Darrell. "Asset Pricing with Heterogeneous Consumers.” Journal of Political Economy, April 1996, 104(2), pp. 219-40.

Dai, Qiang and Singleton, Kenneth J. "Specification Analysis of Affine Term Structure Models.” Journal of Finance, October 2000, 55(5), pp. 1943-78.

Den Haan, Wouter J. "The Term Structure of Interest Rates in Real and Monetary Economies." Journal of Economic Dynamics and Control, July-September 1995, 19(5-7), pp. 909-40.

Dewachter, Hans and Lyrio, Marco. "Macro Factors and the Term Structure of Interest Rates." Journal of Money, Credit, and Banking, February 2006a, 38(1), pp. 119-40.

Dewachter, Hans and Lyrio, Marco. "Learning, Macroeconomic Dynamics and the Term Structure of Interest Rates.” Unpublished manuscript, 2006b.

Diebold, Francis X.; Rudebusch, Glenn D. and Aruoba, S. Boragan. "The Macroeconomy and the Yield Curve: A Dynamic Latent Factor Approach." Journal of Econometrics, March/April 2006, 131(1/2), pp. 309-38.

Diebold, Francis; Piazzesi, Monika and Rudebusch, Glenn D. "Modeling Bond Yields in Finance and Macroeconomics." American Economic Review, May 2005, 95(2), pp. 415-20.

Donaldson, John B; Johnsen, Thore and Mehra, Rajnish. "On the Term Structure of Interest Rates." Journal of Economic Dynamics and Control, JulyOctober 1990, 14(3/4), pp. 571-96.

Duffie, Darrell and Kan, Rui. "A Yield-Factor Model of Interest Rates." Mathematical Finance, October 1996, 6(4), pp. 379-406.

Epstein, Lawrence and Zin, Stanley. "Substitution, Risk Aversion and the Temporal Behavior of Consumption and Asset Returns: A Theoretical Framework." Econometrica, 1989, 57(4), pp. 937-69.

Erceg, Christopher J.; Guerrieri, Luca and Gust, Christopher. "SIGMA: A New Open Economy Model for Policy Analysis." International Journal of Central Banking, March 2006, 2(1), pp. 1-50.

Evans, Charles and Marshall, David. "Economic Determinants of the Term Structure of Nominal Interest Rates." Unpublished manuscript, Federal Reserve Bank of Chicago, 2001.

Favero, Carlo A.; Kaminska, Iryna and Söderström, Ulf. "The Predictive Power of the Yield Spread: Further Evidence and a Structural Interpretation." Unpublished manuscript, Università Bocconi, 2005.

Fuhrer, Jeffrey C. and Rudebusch, Glenn D. "Estimating the Euler Equation for Output." Journal of Monetary Economics, September 2004, 51(6), pp. 1133-53. 
Gallmeyer, Michael F.; Hollifield, Burton and Zin, Stanley E. "Taylor Rules, McCallum Rules and the Term Structure of Interest Rates." Journal of Monetary Economics, July 2005, 52(5), pp. 921-50.

Greenspan, Alan. Monetary Policy Report to the Congress. Board of Governors of the Federal Reserve System, February 16, 2005.

Greenspan, Alan. Monetary Policy Report to the Congress. Board of Governors of the Federal Reserve System, July 20, 2005.

Gürkaynak, Refet S.; Sack, Brian and Swanson, Eric. "The Sensitivity of Long-Term Interest Rates to Economic News: Evidence and Implications for Macroeconomic Models." American Economic Review, March 2005, 95(1), pp. 425-36.

Gürkaynak, Refet S.; Sack, Brian and Wright, Jonathan. "The U.S. Treasury Yield Curve: 1961 to the Present." Finance and Economics Discussion Series 2006-28, Board of Governors of the Federal Reserve System, 2006.

Hamilton, James D. and Kim, Dong Heon. "A Reexamination of the Predictability of Economic Activity Using the Yield Spread." Journal of Money, Credit, and Banking, May 2002, 34(2), pp. 340-60.

Hördahl, Peter; Tristani, Oreste and Vestin, David. "A Joint Econometric Model of Macroeconomic and Term Structure Dynamics." Journal of Econometrics, March-April 2006a, 131(1/2), pp. 405-44.

Hördahl, Peter; Tristani, Oreste and Vestin, David. "The Yield Curve and Macroeconomic Dynamics." Unpublished manuscript, European Central Bank, 2006b.

Kim, Don H. and Wright, Jonathan H. "An ArbitrageFree Three-Factor Term Structure Model and the Recent Behavior of Long-Term Yields and DistantHorizon Forward Rates." Finance and Economics Discussion Series 2005-33, Board of Governors of the Federal Reserve System, 2005.

Kohn, Donald L. "Monetary Policy Perspectives on Risk Premiums in Financial Markets." Presented at the Financial Markets Risk Premiums Conference, Board of Governors of the Federal Reserve System, Washington, DC, July 21, 2005;

www.federalreserve.gov/boarddocs/speeches/2005/.

Kozicki, Sharon and Tinsley, Peter A. "Shifting Endpoints in the Term Structure of Interest Rates." Journal of Monetary Economics, January 2001, 47(3), pp. 613-52.

Kozicki, Sharon and Tinsley, Peter A. "What Do You Expect? Imperfect Policy Credibility and Tests of the Expectations Hypothesis." Journal of Monetary Economics, March 2005, 52(2), pp. 421-47.

Lettau, Martin and Uhlig, Harald. "Can Habit Formation Be Reconciled with Business Cycle Facts?" Review of Economic Dynamics, January 2000, 3(1), pp. 79-99.

Ludvigson, Sydney and Ng, Serena. "Macro Factors in Bond Risk Premia." Unpublished manuscript, New York University, 2006.

Macroeconomic Advisers. "The Rise in Long-Term Interest Rates: A Reason to Stop Sooner.” Monetary Policy Insights Fixed Income Focus (newsletter), April 18, 2006.

McGough, Bruce; Rudebusch, Glenn D. and Williams, John C. "Using a Long-Term Interest Rate as the Monetary Policy Instrument." Journal of Monetary Economics, July 2005, 52(5), pp. 855-79.

Pesenti, Paolo. "The IMF Global Economy Model (GEM): Theoretical Framework.” Unpublished manuscript, International Monetary Fund, 2002.

Ravenna, Federico and Seppälä, Juha. "Monetary Policy and the Term Structure of Interest Rates." Unpublished manuscript, University of California, Santa Cruz, 2006.

Rudebusch, Glenn D. "Do Measures of Monetary Policy in a VAR Make Sense?” International Economic Review, November 1998, 39(4), pp. 907-31.

Rudebusch, Glenn D. "Term Structure Evidence on Interest Rate Smoothing and Monetary Policy Inertia." Journal of Monetary Economics, September 2002, 49(6), pp. 1161-87. 
Rudebusch, Glenn D. "Monetary Policy Inertia: Fact or Fiction?" International Journal of Central Banking, December 2006, 2(4), pp. 85-135.

Rudebusch, Glenn D.; Swanson, Eric and Wu, Tao. "The Bond Yield 'Conundrum' from a MacroFinance Perspective." Monetary and Economic Studies, 2006, 24(S-1), pp. 83-109.

Rudebusch, Glenn D. and Wu, Tao. "A Macro-Finance Model of the Term Structure, Monetary Policy, and the Economy." Working Paper 2003-17, Federal Reserve Bank of San Francisco, 2003 (forthcoming in Economic Journal).

Rudebusch, Glenn D. and Wu, Tao. "Accounting for a Shift in Term Structure Behavior with No-Arbitrage and Macro-Finance Models." Journal of Money, Credit, and Banking, 2007, 39(2-3), pp. 395-422.

Sack, Brian P. "The Cochrane-Piazzesi Return Forecasting Factor and the Term Premium." Unpublished manuscript, Macroeconomic Advisers, 2006a.

Sack, Brian P. "Comment on 'Can Central Banks Target Bond Prices?"” in Monetary Policy in an Environment of Low Inflation: Proceedings of the Bank of Korea International Conference 2006. Seoul, Korea: Bank of Korea, 2006b.
Smets, Frank and Wouters, Raf. "An Estimated Stochastic Dynamic General Equilibrium Model of the Euro Area." Journal of European Economic Association, September 2003, 1(5), pp. 1123-75.

Swanson, Eric; Anderson, Gary and Levin, Andrew. "Higher-Order Perturbation Solutions to Dynamic, Discrete-Time Rational Expectations Models." Working Paper 2006-01, Federal Reserve Bank of San Francisco, 2006.

Wachter, Jessica A. "A Consumption-Based Model of the Term Structure of Interest Rates." Journal of Financial Economics, February 2006, 79(2), pp. 365-99.

Wright, Jonathan. "The Yield Curve and Predicting Recessions." Finance and Economics Discussion Series 2006-7, Board of Governors of the Federal Reserve System, 2006.

Wu, Tao. "Macro Factors and the Affine Term Structure of Interest Rates." Journal of Money, Credit, and Banking, October 2006, 38(7), pp. 1847-75. 


\section{APPENDIX}

\section{Benchmark New Keynesian Model}

To better understand the structural relationship between the term premium and the macroeconomy, we define a simple New Keynesian DSGE model to use as a benchmark. This appendix provides a detailed description of the model, the benchmark parameter values we used in computing the impulse responses in Figures 1 to 3, and our solution algorithm.

The economy contains a continuum of households with a total mass of unity. Households are representative and seek to maximize utility over consumption and labor streams given by

$$
\max E_{t} \sum_{t=0}^{\infty} \beta^{t}\left(\frac{\left(c_{t}-b h_{t}\right)^{1-\gamma}}{1-\gamma}-\chi_{0} \frac{l_{t}^{1+\chi}}{1+\chi}\right),
$$

where $\beta$ denotes the household's discount factor, $c_{t}$ denotes consumption in period $t, l_{t}$ denotes labor, $h_{t}$ denotes a predetermined stock of consumption habits, and $\gamma, \chi, \chi_{0}$, and $b$ are parameters. We will set $h_{t}=C_{t-1}$, the level of aggregate consumption in the previous period, so that the habit stock is external to the household. ${ }^{30}$ The household's stochastic discount factor from period $t$ to $t+j$ thus satisfies

$$
m_{t, t+j} \equiv \beta^{j} \frac{\left(c_{t+j}-b C_{t+j-1}\right)^{-\gamma}}{\left(c_{t}-b C_{t-1}\right)^{-\gamma}} \frac{P_{t}}{P_{t+j}} .
$$

The economy also consists of a continuum of monopolistically competitive intermediate goods firms indexed by $f \in[0,1]$. Firms have Cobb-Douglas production functions:

$$
y_{t}(f)=A_{t} \bar{k}^{\alpha} I_{t}(f)^{1-\alpha}
$$

where $\bar{k}$ is a fixed, firm-specific capital stock (identical across firms) and $A_{t}$ denotes an aggregate technology shock that affects all firms. The level of aggregate technology follows an exogenous AR(1) process:

$$
\log A_{t}=\rho_{A} \log A_{t-1}+\varepsilon_{t}^{A},
$$

where $\varepsilon_{t}^{A}$ denotes an i.i.d. aggregate technology shock with mean zero and variance $\sigma_{A}^{2}$. Intermediate goods are purchased by a perfectly competitive final goods sector that produces the final good with a constant elasticity of substitution production technology:

$$
Y_{t}=\left[\int_{0}^{1} y_{t}(f)^{1 /(1+\theta)} d f\right]^{1+\theta}
$$

Each intermediate goods firm $f$ thus faces a downward-sloping demand curve for its product given by

$$
y_{t}(f)=\left(\frac{p_{t}(f)}{P_{t}}\right)^{-(1+\theta) / \theta} Y_{t},
$$

\footnotetext{
${ }^{30}$ Campbell and Cochrane (1999) consider instead a habit stock, which is an infinite sum of past aggregate consumption with geometrically decaying weights, and a slightly different specification of the utility kernel. They argue that this specification fits asset prices better than the one-period habits used here. However, Lettau and Uhlig (2000) argue that the Campbell-Cochrane specification significantly worsens the model's ability to fit consumption and labor data.
} 
where

$$
P_{t} \equiv\left[\int_{0}^{1} p_{t}(f)^{-1 / \theta} d f\right]^{-\theta}
$$

is the constant elasticity of substitution aggregate price of a unit of the final good.

Each firm sets its price, $p_{t}(f)$, according to a Calvo contract that expires with probability $1-\xi$ each period. There is no indexation, so the price, $p_{t}(f)$, is fixed over the life of the contract. When a contract expires, the firm is free to reset its price as it chooses. In each period $t$, firms must supply whatever output is demanded at the posted price, $p_{t}(f)$. Firms hire labor, $l_{t}(f)$, from households in a competitive labor market, paying the nominal market wage, $w_{t}$. Marginal cost for firm $f$ at time $t$ is thus given by

$$
m c_{t}(f)=\frac{w_{t} l_{t}(f)}{(1-\alpha) y_{t}(f)} .
$$

Firms are collectively owned by households and distribute profits and losses back to the households. When a firm's price contract expires and it is able to set a new contract price, the firm maximizes the expected present discounted value of profits over the lifetime of the contract:

$$
E_{t} \sum_{j=0}^{\infty} \xi^{j} m_{t, t+j}\left[p_{t}(f) y_{t+j}(f)-w_{t+j} l_{t+j}(f)\right],
$$

where $m_{t, t+j}$ is the representative household's stochastic discount factor from period $t$ to $t+j$. The firm's optimal contract price, $p_{t}^{*}(f)$, thus satisfies

$$
p_{t}^{*}(f)=\frac{(1+\theta) E_{t} \sum_{j=0}^{\infty} \xi^{j} m_{t, t+j} m c_{t+j}(f) y_{t+j}(f)}{E_{t} \sum_{j=0}^{\infty} \xi^{j} m_{t, t+j} y_{t+j}(f)} .
$$

To aggregate up from firm-level variables to aggregate variables, it is useful to define the crosssectional price dispersion, $\Delta_{t}$ :

$$
\Delta_{t}^{1 /(1-\alpha)} \equiv(1-\xi) \sum_{j=0}^{\infty} \xi^{j} p_{t-j}^{*}(f)^{-(1+\theta) /(\theta(1-\alpha))},
$$

where the exponent $1 /(1-\alpha)$ arises from the firm-specificity of capital. ${ }^{31}$ We can then write

$$
Y_{t}=\Delta_{t}^{-1} A_{t} \bar{K}^{\alpha} L_{t}^{1-\alpha},
$$

where $\bar{K}=\bar{k}$ and

$$
L_{t} \equiv \int_{0}^{1} l_{t}(f) d f
$$

and equilibrium in the labor market requires $L_{t}=l_{t}$, where $l_{t}$ is the labor supplied by households.

Optimizing behavior by households gives rise to the intratemporal condition,

$$
\frac{w_{t}}{P_{t}}=\frac{\chi_{0} l_{t}^{\chi}}{\left(c_{t}-b C_{t-1}\right)^{-\gamma}}
$$

\footnotetext{
${ }^{31}$ Allowing a competitive capital market with free mobility of capital across sectors or considering industry-specific labor markets as well as firm-specific capital does not alter our basic findings presented in the benchmark model section.
} 


\section{Rudebusch, Sack, Swanson}

and the intertemporal Euler equation,

$$
\left(c_{t}-b C_{t-1}\right)^{-\gamma}=\beta \exp \left(i_{t}\right) E_{t}\left(c_{t+1}-b C_{t}\right)^{-\gamma} P_{t} / P_{t+1},
$$

where $i_{t}$ denotes the continuously compounded interest rate on the riskless one-period nominal bond. There is no investment in physical capital in the model.

There is a government in the economy, which levies lump-sum taxes, $G_{t}$, on households and destroys the resources it collects. The aggregate resource constraint implies that

$$
Y_{t}=C_{t}+G_{t},
$$

where $C_{t}=C_{t}$, with $c_{t}$ denoting the consumption of the representative household. Government consumption follows an exogenous $\operatorname{AR}(1)$ process:

$$
\log G_{t}=\rho_{G} \log G_{t-1}+\varepsilon_{t}^{G},
$$

where $\varepsilon_{t}^{G}$ denotes an i.i.d. government consumption shock with mean zero and variance $\sigma_{G}^{2}$.

Finally, there is a monetary authority in the economy that sets the one-period nominal interest rate according to a Taylor-type policy rule:

$$
i_{t}=\rho_{i} i_{t-1}+\left(1-\rho_{i}\right)\left[i^{*}+g_{y}\left(Y_{t}-Y_{t-1}\right)+g_{\pi} \pi_{t}\right]+\varepsilon_{t}^{i},
$$

where $i^{*}$ denotes the steady-state nominal interest rate, $\pi_{t}$ denotes the inflation rate (equal to $P_{t} / P_{t-1}-1$ ), $\varepsilon_{t}^{i}$ denotes an i.i.d. stochastic monetary policy shock with mean zero and variance $\sigma_{i}^{2}$, and $\rho_{i}$, $g_{y}$, and $g_{\pi}$ are parameters. Of course, the steady-state inflation rate, $\pi^{*}$, in this economy must satisfy $1+\pi^{*}=\beta \exp \left(i^{\star}\right)$.

As noted above, households have access to a long-term default-free nominal consol that pays one dollar every period in perpetuity. The nominal consol's price, $p_{t}^{(\infty)}$, thus satisfies

$$
p_{t}^{(\infty)}=1+E_{t} m_{t+1} p_{t+1}^{(\infty)},
$$

where $m_{t+1} \equiv m_{t, t+1}$ is the representative household's stochastic discount factor. We define the riskneutral consol price, $p_{t}^{(\infty) r n}$, to be

$$
p_{t}^{(\infty) r n}=1+\exp \left(-i_{t}^{(1)}\right) E_{t} p_{t+1}^{(\infty) r n},
$$

and the implied term premium is then given by

$$
\log \left(\frac{p_{t}^{(\infty)}}{p_{t}^{(\infty)}-1}\right)-\log \left(\frac{p_{t}^{(\infty) r n}}{p_{t}^{(\infty) r n}-1}\right) .
$$

Note that under our baseline parameterization, the consol in our model has a duration of about 25 years.

This completes the specification of the benchmark model referred to in the text. In computing impulse response functions, we use the parameter values as specified in Table A1. A technical issue that arises in solving the model above is the relatively large number of state variables, eight in all: $C_{t-1}$, $A_{t-1}, G_{t-1}, i_{t-1}, \Delta_{t-1}$, plus the three shocks $\varepsilon_{t}^{A}, \varepsilon_{t}^{G}, \varepsilon_{t}^{i}{ }^{32}$ Because of dauntingly high dimensionality, valuefunction iteration-based methods, such as projection methods (or, even worse, discretization methods), are computationally intractable. We instead solve the model above using a standard macroeconomic

\footnotetext{
32 The number of state variables can be reduced a bit by noting that $G_{t}$ and $A_{t}$ are sufficient to incorporate all of the information from $G_{t-1}$, $A_{t-1}$, $\varepsilon_{t}^{G}$, and $\varepsilon_{t}^{A}$, but the basic point remains valid-namely, that the number of state variables in the model is large from a computational point of view.
} 
technique that approximates the model's solution around the nonstochastic steady state-a socalled perturbation method.

As discussed in the text, a first-order approximation (i.e., a linearization or log-linearization) of the model around the steady state eliminates the term premium from the model entirely, because equations (40) and (41) are identical in the first-order approximation. A second-order approximation produces a nonzero but constant term premium (a sum of the variances $\sigma_{A}^{2}, \sigma_{G}^{2}$, and $\sigma_{i}^{2}$ ). Because our interest in this paper is not just in the level of the term premium but also in its variation over time, we must compute a thirdorder approximation to the solution of the model around the nonstochastic steady state. We do so using the $n$ th-order perturbation AIM algorithm of Swanson, Anderson, and Levin (2006). This algorithm requires that the equations of the model be put into a recursive form, which for the model above is fairly standard. The most difficult equation is (31), which can be written in recursive form as

$$
\begin{aligned}
\left(\frac{p_{t}^{*}(f)}{P_{t}}\right)^{1+\frac{\alpha}{1-\alpha} \frac{1+\theta}{\theta}} & =\frac{z_{n, t}}{z_{d, t}} \\
z_{d, t} & =Y_{t}\left(C_{t}-b C_{t-1}\right)^{-\gamma}+\beta \xi E_{t} \pi_{t+1}^{1 / \theta} z_{d, t+1} \\
z_{n, t} & =(1+\theta) \frac{\chi_{0}}{1-\alpha} L_{t}^{1+\chi} \Delta_{t}^{-1 /(1-\alpha)}+\beta \xi E_{t} \pi_{t+1}^{\frac{1+\theta}{\theta}} \frac{1}{1-\alpha} Z_{n, t+1 .}
\end{aligned}
$$

The computational time required to solve our model to the third order is minimal-no more than about 10 seconds on a standard laptop computer.

Computing impulse responses for this model is actually simpler than the use of a third-order approximation might suggest. We are interested in the responses of output and the term premium to an exogenous shock to $\varepsilon_{t}^{A}$, $\varepsilon_{t}^{G}$, or $\varepsilon_{t}^{i}$. For output, we plot the standard first-order (i.e., log-linear) responses of output to each shock. For small shocks, such as those of the size we are considering here (1 percent), these responses are highly accurate. For the term premium, of course, the first- and second-order responses of that variable to each shock would be identically zero, so we plot the third-order responses of that variable. These third-order terms are all of the form $\sigma_{Z}^{2} X$, where $Z \in\{A, G, i\}$ and $X$ is one of the state variables of the model, ${ }^{33}$ so if we plug in the values of $\sigma_{A}^{2}, \sigma_{G}^{2}$, and $\sigma_{i}^{2}$ given in Table A1, these terms are linear as well, which makes them easy to plot.

\footnotetext{
${ }^{33}$ In perturbation analysis, stochastic shocks of the model are given an auxiliary "scaling” parameter, so these shocks are third-order in a rigorous sense. See Swanson, Anderson, and Levin (2006) for details.
} 
